OPEN ACCESS

Edited by:

Hadi Nur,

University of Technology Malaysia,

Malaysia

Reviewed by:

Pedro Almendros,

Spanish National Research Counci

(CSIC), Spain

Tomoo Mizugaki,

Osaka University, Japan

*Correspondence:

Marta Marín-Luna

mmarin@uvigo.es

Carlos Silva López

carlos.silva@uvigo.es

Specialty section:

This article was submitted to

Catalysis and Photocatalysis,

a section of the journal

Frontiers in Chemistry

Received: 20 February 2019

Accepted: 11 April 2019

Published: 14 May 2019

Citation:

Marín-Luna M, Nieto Faza O and Silva López C (2019) Gold-Catalyzed Homogeneous (Cyclo)/somerization Reactions. Front. Chem. 7:296 doi: $10.3389 /$ fchem.2019.00296

\section{Gold-Catalyzed Homogeneous (Cyclo)Isomerization Reactions}

\author{
Marta Marín-Luna*, Olalla Nieto Faza and Carlos Silva López* \\ Departamento de Química Orgánica, Universidade de Vigo, Vigo, Spain
}

Gold is currently one of the most used metals in organometallic catalysis. The ability of gold to activate unsaturated groups in different modes, together with its tolerance to a wide range of functional groups and reaction conditions, turns gold-based complexes into efficient and highly sought after catalysts. Natural products and relevant compounds with biological and pharmaceutical activity are often characterized by complex molecular structures. (Cyclo)isomerization reactions are often a useful strategy for the generation of this molecular complexity from synthetically accessible reactants. In this review, we collect the most recent contributions in which gold(I)- and/or gold(III)-catalysts mediate intramolecular (cyclo)isomerization transformations of unsaturated species, which commonly feature allene or alkyne motifs, and organize them depending on the substrate and the reaction type.

Keywords: gold, catalysis, isomerization, allenes, 1 , $n$-enynes, $1, n$-diynes

\section{INTRODUCTION}

Historically, most civilizations have considered gold as synonym of power, purity, beauty and wealth. In contrast, for a long time, gold was chemically ignored and misconceived as an inert element. It was only at the end of the twentieth century and the beginning of the twenty first when a "gold rush" in synthesis started with the publication of the original works of Fukuda (Fukuda and Utimoto, 1991), Teles (Teles et al., 1998), and Tanaka (Mizushima et al., 2002) on the homogeneous gold-catalyzed addition of water and alcohol to alkynes. The seminal contributions that sparked the interest in gold catalysis in the ending years of the twentieth century were due to Hashmi et al. who showed the catalytic reactivity of $\mathrm{AuCl}^{3}$ on cycloisomerization reactions of alkyne-based compounds leading to furans and arenes (Hashmi et al., 2000; Stephen et al., 2000). Since then the interest on this metal has increased notably as revealed by the vast number of publications on gold catalysis ${ }^{1}$. Located in group 11 of the periodic table, gold behaves as a soft carbophilic Lewis acid with the ability to stabilize an adjacent carbocation through back-donation. Relativistic effects in this atom promote the contraction of its $6 s$ orbital, which becomes the main reason for this relatively uncommon behavior across the periodic table (Gorin and Toste, 2007; Faza and López, 2015). Nevertheless, gold complexes are usually poorly-reactive in their precatalytic state and they need prior transformation in-situ, most commonly through the abstraction of one ligand, generally a chloride group. Among others, silver salts are the most used agents for this purpose (Ranieri et al., 2015). Furthermore, both the electronic nature of ligands (Wang et al., 2012; Ebule et al., 2016; Gung et al., 2016; Ferrer and Echavarren, 2018a) and of the counterion (Homs et al., 2014; Ciancaleoni et al., 2015; Jia and Bandini, 2015; Rocchigiani et al., 2015; Gatto et al., 2016; Yuan et al., 2018; Schießl et al., 2018a,b) have a significant influence on the reactivity of the gold-catalyzed processes. 


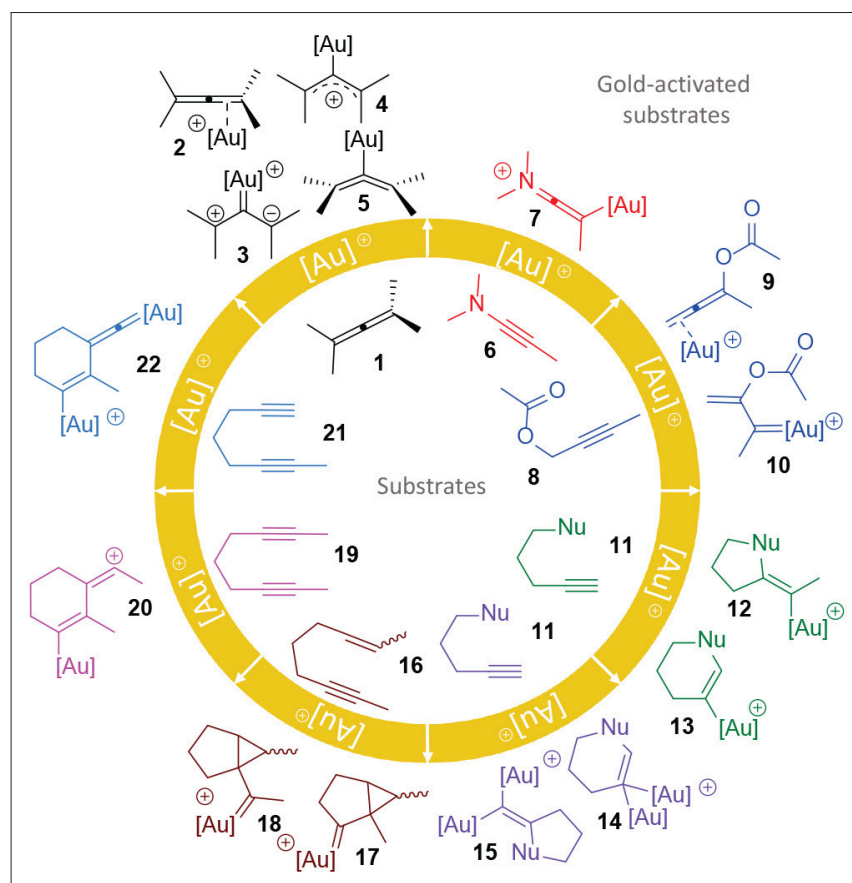

FIGURE 1 | Gold activation reaction patterns toward different unsaturated substrates.

Thus, gold(I)- and gold(III)-complexes are mostly intended for the activation of unsaturated groups, such as allene and alkyne derivatives (Jones, 2015; Blons et al., 2018). Figure 1 shows the possible activation modes exerted by a generic cationic gold complex $[\mathrm{Au}]^{+}$toward common starting materials which will be the subject of revision in this report. Four possibilities have been described for the coordination of gold to an allene moiety 1: $\eta^{2}$-coordinated complexes (2), zwitterionic carbenes (3), $\sigma$-allylic cations (4) or $\eta^{1}$-coordinated bent allenes (5) (Soriano and Fernández, 2014). Cumulenic derivatives could also be formed under gold activation. The $\pi$-coordination of gold to the alkyne group of an ynamide substrate $\mathbf{6}$ promotes the formation of an electrophilic keteniminium ion 7 susceptible to a nucleophilic attack. Propargylic carbonate/ester substrates $\mathbf{8}$ are prone to rearrange under gold-catalysis, usually trough a 1,3- or 1,2-migration of the carbonate/ester group over the $\pi$-system toward either the allene intermediate 9 or the gold-carbene 10, respectively (Ghosh et al., 2014; Swift and Gronert, 2016). Alkynes containing and internal nucleophilic functional group 11 can cyclize either in an exo-dig or endo-dig fashion leading to 12 and 13. Otherwise, it is possible that two gold complexes coordinate simultaneously to the terminal alkyne $\mathbf{1 1}$ forming a $\sigma, \pi$-digold alkyne and then furnishing intermediates $\mathbf{1 4}$ and $\mathbf{1 5}$ (Cheong et al., 2008; Larsen et al., 2015). Cyclopropane gold carbene-like intermediates $\mathbf{1 7}$ and $\mathbf{1 8}$ are, respectively, achieved through an endo-dig and an exo-dig carbocyclization of the enyne 16 (Obradors and Echavarren, 2014). Two internal alkynes placed

\footnotetext{
${ }^{2}$ The Scopus database returns 30,000 entries when looking for gold catalyst, gold cataysis or gold-mediated keywords (search performed in January 2019)
}

in an diyne 19 can react onto each other under gold- $\pi$-activation forming a conjugated vinyl cation intermediate 20. Recently, the possibility of dual gold-activation has started to garner attention. It is a reactivity pattern for diyne systems, in which one gold center simultaneously enhances the nucleophilic character of the terminal alkyne trough a $\sigma$-bond while a second gold center turns the other alkyne motif more electrophilic trough a classical $\pi$-coordination (Cheong et al., 2008; Odabachian et al., 2009; Stephen et al., 2012; Ye et al., 2012; Hashmi, 2014). This reactivity is represented in the transformation of dyine 21 toward intermediate 22. The diversity in the activation patterns shown by gold opens a large window of possibilities for the use of this metal as a powerful tool in the design and synthesis of relevant compounds in different fields. In fact, an increasing number of structurally complex molecules, such as natural products, biologically active compounds or polycyclic systems are reachable from synthetically accessible alkyne, alkene and allene reagents under metal-mediated isomerization process (Aubert et al., 2011; Yamamoto, 2012; Zhang et al., 2012; Stathakis et al., 2016; Hu et al., 2017; Herndon, 2018). In this sense, gold shines over other metals mostly due to its tolerance to diverse functional groups, low toxicity and the usually mild thermal conditions that are required to run these kind of transformations, in some occasions even showing tolerance to aqueous media or green solvents (Gatto et al., 2018).

This review focuses on homogeneous gold-mediated intramolecular (cyclo)isomerizations without the direct intervention of external agents in the intermediate mechanistic steps, except water in some unavoidable cases. It is organized according to both the kind of substrates to be activated by the gold complex: Allenes, 1,n-dienynes and 1,n-diynes and to the first mechanistic step in the global transformation such as carbocyclization, nucleophilic attack or carbonate/ester group rearrangement processes. Due to the overwhelming number of studies and the recently published reviews about gold-mediated isomerization reactions (Belmont and Parker, 2009; Fensterbank and Malacria, 2014; Yang and Hashmi, 2014; Dorel and Echavarren, 2015; Asiri and Hashmi, 2016; Day and Chan, 2016; Maes et al., 2016; Quintavalla and Bandini, 2016; Siva Kumari et al., 2016; Wei and Shi, 2016; García-Morales and Echavarren, 2018; Lee and Kumar, 2018; McGee et al., 2018; Toullec and Michelet, 2018), we will include here the most relevant contributions of the last years.

\section{GOLD-CATALYZED ISOMERIZATION PROCESSES INVOLVING ALLENES}

Allenes are cumulenic compounds in which one carbon atom stablishes a $\pi$-bond with two adjacent carbon centers, adopting an ideal bond angle of $180^{\circ}$ (Patel and Bharatam, 2011; Soriano and Fernández, 2014). Both the structural architecture of this triatomic system and the electronic nature of the substituents on it direct the metal coordination modes and therefore the reactivity of the activated allene (Figure 1). In addition, the initial mode in which gold coordinates to the cumulenic motif, and the further transformations, determines the spatial disposition 


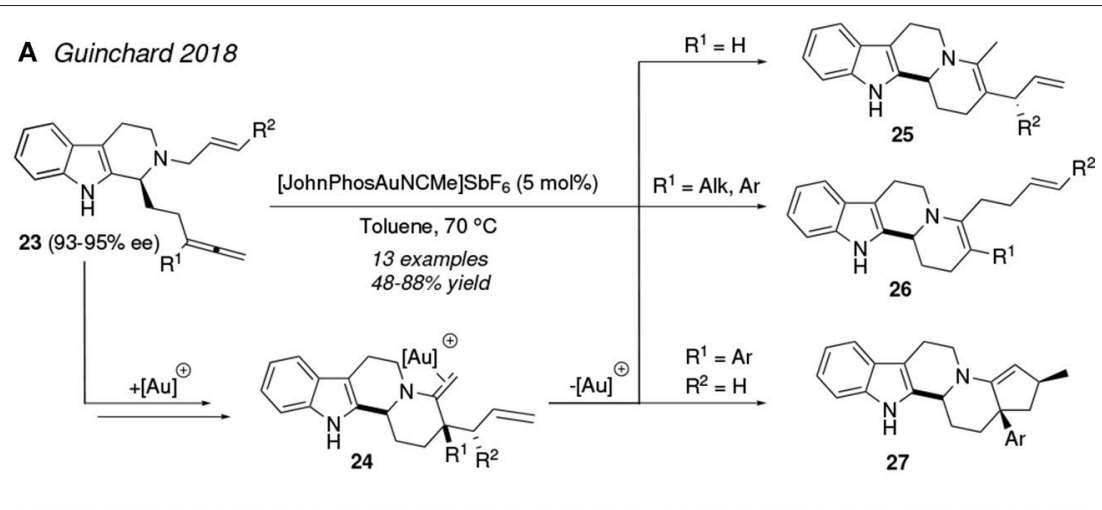

B Alcaide 2018
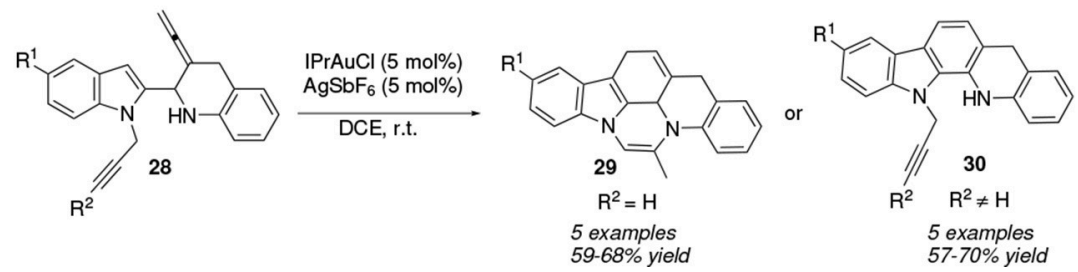

FIGURE 2 | Gold-mediated cycloisomerization of allene derivatives.

of the substituents observed in the isomeric products (Yang and Hashmi, 2014) and even turns the mechanistic pathway away from that of the uncatalyzed reaction (Mandal and Datta, 2018). Interestingly, gold complexes are able to catalyze the racemization of 1,3-disubstituted allenes, a process which has been theoretically studied for the particular case of IPrAuOTf acting as the catalyst (Li et al., 2016).

In 2018, Guinchard et al. reported an elegant thermal ring closure of enantionenriched $N$-allyltryptamines 23 catalyzed by the Echavarren catalyst, [JohnPhosAuNCMe] $\mathrm{SbF}_{6}$ (Figure 2A). The initial gold(I)-activation of the allene motif promotes the tandem 6-exo-dig/aza-Cope rearrangement process affording intermediates 24. The nature of the $\mathrm{R}^{1}$ and $\mathrm{R}^{2}$ substituents placed at both the original allene and alkene groups direct the subsequent evolution of $\mathbf{2 4}$ toward the different indolo[2,3a]quinazolines 25, 26 and 27. Thus, for $\mathrm{R}^{1}=\mathrm{H} 24$ undergoes an isomerization process of the exocyclic $\mathrm{C}-\mathrm{C}$ double bond yielding 25 whereas when $\mathrm{R}^{1}$ = alkyl, aryl the mechanism evolves trough a [3,3]-Cope rearrangement to afford compounds 26. Pentacyclic substrates 27 were isolated for the special case of $\mathrm{R}^{1}=\operatorname{aryl}$ and $\mathrm{R}^{2}=\mathrm{H}$ (Gobé et al., 2018). In the same line, the (non-)substitution at the terminal position of the alkyne group contained in the initial indole-tethered amino allenynes $\mathbf{2 8}$ is the responsible for the divergent synthesis of the fused polyciclic indoles 29 and 30 (Figure 2B). [IPrAu] ${ }^{+}$would activate the allene group toward a 6-endo-carboauration at the $\mathrm{C} 3$ atom of the indole ring as initial step whereas the subsequent hydroamination process over the $\mathrm{N}$-pendant terminal alkyne ends in the hexacycle 29. This process does not occur in the case of alkynes bearing bulky $\mathrm{R}^{2}$ groups. Pentacycles $\mathbf{3 0}$ are therefore accessed in these latter transformations (Alcaide et al., 2018).
Other gold-mediated carbocyclization reactions have been described for allenes. Daphnane/tigliane diterpene natural products contain a common scaffold based on a 5-7-6 carbotricyclic ring system. In this sense, $\mathrm{Li}$ et al. published a gold(I)-mediated sequential transformation of allenynes 31 into the polycyclic ethers 33 (Figure 3A). The authors noted that the overall direct gold-catalyzed process was unfruitful, requiring the optimization of a two-step sequence under different reaction conditions and gold(I)-complexes. Thus, $\left[\mathrm{PPh}_{3} \mathrm{Au}\right]^{+}$promotes the initial 5-exo-dig hydroalkoxylation onto the alkyne group toward intermediates 32 (Riedel et al., 2017) which subsequently undergo a furan-allene $(4+3)$ cycloaddition under thermal treatment $\left(60^{\circ} \mathrm{C}\right)$, and with the participation of [tBuXPhosAu $]^{+}$, to afford the isomeric mixture of the desired product 33 plus 33'. This last step is highly influenced by the nature of the $\mathrm{R}^{1}$ substituent at the allene site. Terminal allenes $\left(\mathrm{R}^{1}=\mathrm{H}\right)$ are poor substrates for this $(4+3)$ cycloaddition, producing a complex mixture of products whereas tricyclic systems $33 \mathbf{b}$ and 33c are obtained in good yields and with a moderate isomeric ratio for the target product 33 vs. the undesired ether (Li et al., 2017b).

In 2017, the combination of gold(I) and copper(II) complexes was reported as an efficient catalyst to promote the site- and regiocontrolled carbocyclization of a racemic mixture of allenes 34. In order to explain the mechanistic sequence behind these transformations Schomaker et al. proposed a double metal activation in which $\mathrm{Cu}(\mathrm{OTf})_{2}$ would form a Cu-enolate chelate whereas $\left[\mathrm{R}_{3} \mathrm{PAu}\right]^{+}(\mathrm{R}=\mathrm{Ph}$ or $\mathrm{Cy})$ would activate the allene motif (35) to then furnish the cylopentene species 36 in $>1: 1$ $\mathrm{dr}$ (anti:syn of the two starred carbon centers). Remarkably, the stereochemistry at the junction of the two 5-member rings at 36 remains syn during the process. The different dr observed in 
A $\quad$ Li 2017

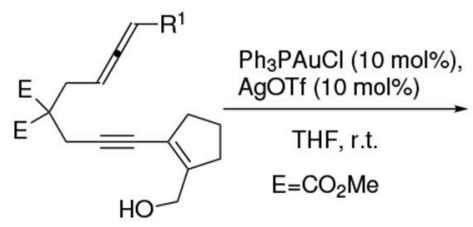

31a, $\mathrm{R}^{1}=\mathrm{H}$

31b, $\mathrm{R}^{1}={ }^{\mathrm{n}} \mathrm{Pr}$

31c, $\mathrm{R}^{1}=\mathrm{CH}_{2} \mathrm{OBn}$

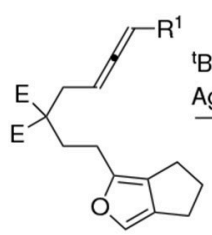

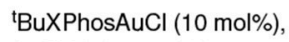
$\mathrm{AgSbF}_{6}(10 \mathrm{~mol} \%)$

DCE, $60^{\circ} \mathrm{C}$
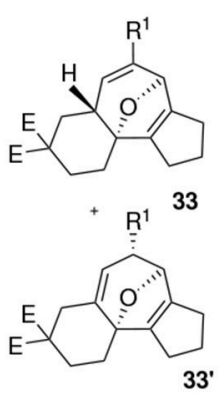

$33 \mathbf{a}+33 \mathbf{a} \mathbf{a}^{\prime},-$

$33 \mathbf{b}+33 \mathbf{b}^{\prime}, 74 \%, 1.4: 1$

$33 \mathrm{c}+33 \mathrm{c}^{\prime}, 60 \%, 1.8: 1$

B Schomaker 2017

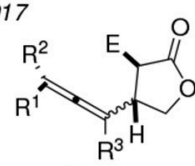

34 $+[\mathrm{Cu}]$
$+[\mathrm{Au}]^{\oplus}$
. 32a, $68 \%$

32c, $63 \%$
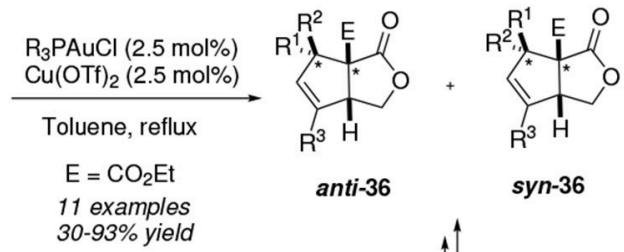

anti-36

syn-36

$$
30-93 \% \text { yield }
$$

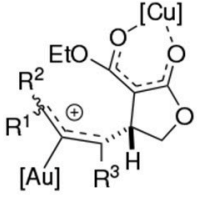

$-[\mathrm{Cu}]$

$-[\mathrm{Au}]^{\oplus}$

FIGURE 3 | Gold-mediated cycloisomerization of allene derivatives.

A Voituriez 2017
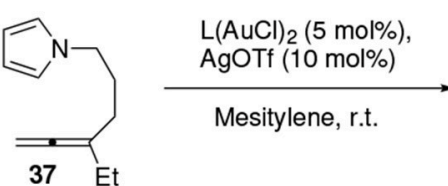

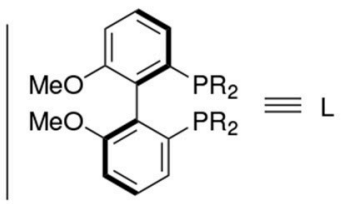

B Zhang 2017

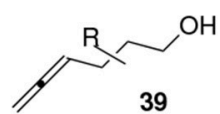

(R)-L2AuCl (0.01 mol\%),

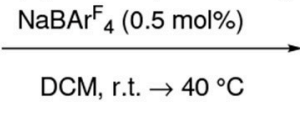

14 examples $>90 \%$ ee

$65-99 \%$ yield<smiles>C=C[C@H]1CCCO1</smiles><smiles>COc1ccc2ccccc2c1-c1c(OC)c(C(=O)N(C)C)cc2ccccc12</smiles>

FIGURE 4 | Cycloisomerization of allene derivatives by chiral gold-catalysts.

products 36 respect to the 1:1 dr in the initial mixture of allenes 34 is reasoned assuming that the rate of the gold-activated allene epimerization is faster than that of the carbocyclization process at the intermediate 35 (Figure 3B) (Reeves et al., 2017).

In the last few years many chemists have focused their efforts in developing enantioselective reactions, which is currently one of the most active arenas in the field of gold catalysis (Wang et al., 2014). An illustrative example is that published by
Voituriez et al. in the course of the total synthesis of the natural product (-)-rhazinilam. They reported the use of a digold(I) complex attached to the chiral biphenyl-phosphine ligand $\mathrm{L}$ to mediate in the enantionselective 6-exo-trig cycloisomerization of the allene-functionalized pyrrole 37, which leads to the tetrahydroindolizine derivative 38 in $89 \%$ yield and $83 \%$ ee. This reaction is conducted in a solution of mesitylene at room temperature (Figure 4A) (Magné et al., 2017). 
In the same line, asymmetric gold-catalysis via the combined use of a non-spectator chiral ligand and a metal center has been described for the cyclization of the 4-allen-1-ol substrates 39 affording chiral 2-substituted tetrahydrofurans $\mathbf{4 0}$ (>90\% ee, Figure 4B). The pendant amide group at the chiral binaphtylbased ligand (R)-L2 seems to play a crucial role in the rate acceleration of the reaction due to its abilities to act as general base. Authors propose that the preferred gold-allene coordination is that in which that amide group is placed close to the alcohol group, whereby forming a hydrogen bond $\mathrm{C}=\mathrm{O} \cdots \mathrm{H}$ $\mathrm{O}$ which increases the nucleophilicity of the oxygen atom and thus the rate of the reaction (Wang et al., 2017a).

Furthermore, the highly stereoselective cycloisomerization of optically active 4,5-alkadienoic acids leading to gammabutyrolactones has been reported to occur under catalysis of chiral gold-complexes (Zhou et al., 2018a). Also, nonchiral gold catalysts have been reported to promote related cycloisomerizations of cumulenols (Alcaide et al., 2016) or allenols (Lempke et al., 2016). For this later example, the effects governing the mechanism of the gold-catalyzed attack mode of hydroxylamines onto allenes yielding either dihydrooxazine or $\mathrm{N}$-hydroxypyrroline derivatives (that is $\mathrm{O}$ - vs. NH-attack and 5- vs. 6-member ring formation) were computationally studied and described in detail by Silva and coworkers in 2017 (Kiriakidi et al., 2017).

\section{GOLD-CATALYZED ISOMERIZATION PROCESSES INVOLVING AN INITIAL ALKYNE ACTIVATION}

Most of the studies on gold-mediated isomerization reactions are devoted to the transformation of alkynes bearing a second insaturation (an alkene or alkyne group), that is $1, n$-enyne and 1,n-diyne substrates (Jiménez-Núñez and Echavarren, 2008; Asiri and Hashmi, 2016; Day and Chan, 2016; Lee and Kumar, 2018). Nonetheless, cycloisomerization processes have also been described in molecules containing solely a reactive alkyne or alkene group. This is the case of the gold(I)-directed ringcontraction process of cyclooctyne to 5 -member bicyclic alkenes (Das et al., 2016) or the intramolecular hydroamination of 6-alkenyl-2-pyridones to yield 1,6-carboannulated 2-pyridones (Timmerman et al., 2017). In those circumstances where both types of unsaturations are present, the well-known preference of gold for alkyne over alkene groups is rationalized in terms of the HOMO-LUMO energy gap of the coordinated $\pi$ systems rather than through intrinsic considerations of the metal itself (Gorin and Toste, 2007). Henceforth, (cyclo)isomerization processes initiated by the gold activation of an alkyne group will be described.

\subsection{Gold-Catalyzed Cycloisomerization of Ynamides}

Ynamides are special amines substituted by an alkyne group and an electro-withdrawing group which modulate its stability and reactivity (Pan et al., 2016). Yeh et al. reported the gold(I)catalyzed double cyclization of the 3-enynamides 41 in dichloromethane at room temperature (Figure 5A). The authors
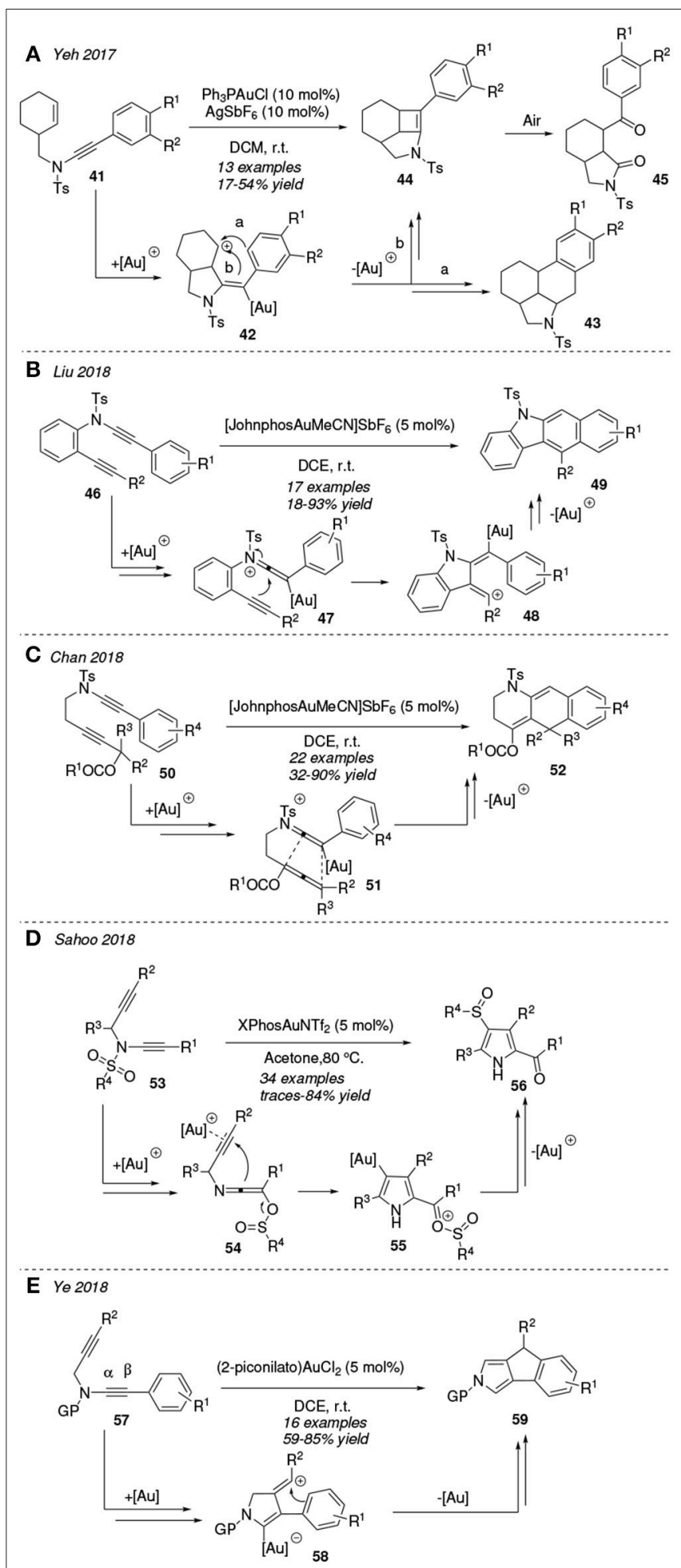

FIGURE 5 | Gold-mediated cycloisomerization processes of ynamides.

propose an initial cyclization involving the gold-activated alkyne motif and the pendant endocyclic $\mathrm{C}=\mathrm{C}$ bond that provides vinyl cation 42. This cationic intermediate 42 could cyclize forming either a 6-member ring, by attack of the pendant phenyl ring 
onto the deficient carbon center (path a toward 43, traces) or a 4-member ring, involving the exocyclic alkene (path $b$ leading to 44). The strained cyclobutene compounds 44 are quickly oxidized when exposed to air, affording the respective 1,4diketones compounds $\mathbf{4 5}$, which are isolated as major products (Zhong et al., 2017).

In 2018, Liu et al. designed a new route toward benzo[b]carbazoles 49 involving the $[J o h n P h o s A u N C M e]^{+}$. catalyzed cycloisomerization of the ynamide-ynes 46 via a formal dehydro-Diels-Alder reaction at room temperature (Figure 5B). Initial gold-activated keteniminium ions 47 undergo a cyclization affording the vinyl cations $\mathbf{4 8}$ which evolve toward the final tetracycles 49 by a benzoannulation reaction (Xu et al., 2018). The same catalyst, [JohnPhosAuNCMe]SbF ${ }^{6}$, mediates the transformation of ynamides $\mathbf{5 0}$ into tetrahydro $[g]$ quinolines 52 (Figure 5C). An initial [3,3]-sigmatropic rearrangement of the acetate group and activation of the ynamide group would yield the keteniminium ion $\mathbf{5 1}$ which would experiment a formal [4+2]-cycloaddition yielding 52. This protocol is efficient even in the presence of air and moisture, indicating the tolerance of the gold catalysts to diverse reaction conditions (Chen et al., 2018).

A very interesting case is that of $N$-substituted ynamides decorated with functional groups with migratory abilities. Figure 5D shows the unconventional thermal transformation of $N$-sulfonyl ynamides 53 to 4 -sulfinylated pyrrol derivatives 56 in presence of $\mathrm{XPhosAuNTf}_{2}$ catalyst. The authors proposed a mechanism initiated by a $[1,3]$-sulfonyl migration from the $\mathrm{N}$ atom to the distal carbon atom of the alkyne fragment resulting in intermediate 54. The subsequent gold-activation of the alkyne moiety promotes an umpolung at the unsaturations and facilitates a 5-endo-dig cyclization toward 55, which is transformed into the indole $\mathbf{5 6}$ via a deaurative $[1,5]$-sulfinylation process. This kind of sulfonyl/sulfinyl shift proceeds in a regioselective fashion. These results were also supported by a computational study (Sahoo et al., 2018).

Furthermore, gold(III)-complexes are able to promote the activation of ynamides toward cycloisomerization reactions. In 2018 , Ye et al. reported the practical synthesis of indeno[1,2c]pyrroles 59 in good yields under mild conditions from $\mathrm{N}$ propargyl ynamides $\mathbf{5 7}$ and with gold(III) catalysis. In contrast to the usual metal-catalyzed cyclization of $\pi$-tethered ynamides over the central $\alpha$-carbon atom, authors reported a regioselective attack on the $\beta$-carbon of the ynamide $\mathbf{5 7}$ leading to the vinyl cation 58, mostly associated to a lower ring strain of the formed pentacycle with respect to the four-member ring alternative (Figure 5E) (Shen et al., 2018).

\subsection{Gold-Catalyzed Cycloisomerization of $1, n$-dienynes and 1,n-diynes Containing a Propargyl Carbonate/Ester}

In the last 3 years a great number of studies devoted to goldmediated cyclizations of compounds containing a propargylic carbonate/ester motif have been reported. It is worth to note that the usual initial carboxy rearrangement determines the fate and further transformations that encompass this chemistry. For this reason substrate design is key to successfully obtain the desired target molecule through these reactions. Recently, Zhang et al. introduced the application of frustrated Lewis pairs as a synthetic strategy, that is, basic tertiary amine as ligands to design gold cationic complexes which improve the regio- and stereoselective ratios of propargylic ester isomerizations (Wang et al., 2017b). In this sense, related $1, n$-enyne derivatives are well-exploited reactants and powerful synthethic tools to build carbonyl-based compounds. Figure 6A describes the diasterospecific synthesis of cyclopentanones $\mathbf{6 2}$ owning two contiguous stereogenic carbons published by Tius et al. The authors use a gold(I) complex to catalyze a tandem [1,3]-OAc shift/cyclization/acetate hydrolysis process. This cycloisomerization reaction can be conducted at room temperature with substrates 60 bearing different functional groups such as esters, $-\mathrm{CF}_{3}$ or alkyl chains. The high diastereoselectivity observed in the transformation is related to the rapid alkenyl isomerization of the pentadienyl intermediate $\mathbf{6 1}$ (Congmon and Tius, 2018).

A couple of years earlier, the preparation of benzazocines 66 was accomplished from terminal 1,9-enynyl esters 63 through a gold-catalyzed cascade reaction. Xie et al proposed the initialization of the mechanism with a 1,2-acyloxy shift that further evolves with a $O$-cyclization to yield 1,3 dipolar intermediates $\mathbf{6 4}$. These 64 species engage in a [3+2] cycloaddition reaction involving the terminal alkene to afford the polycyclic scaffolds 65 , which convert into the final substituted benzocines $\mathbf{6 6}$ by a hydrolisis process. Two different diastereoisomers were isolated and fully characterized, the trans isomers $\mathbf{6 6}$ being the major products of the reaction (Figure 6B) (Feng et al., 2016). The same group has reported on the successful attempts to obtain complex tetracyclic frameworks by appliying a similar gold-catalyzed protocol on related linear enynyl esters (Sun et al., 2017).

Liu et al. published the gold(I)-mediated diastereoselective formation of 8-oxabicyclo[3.2.1] octanes 70 from glycal bearing porpargylic esters 67 (Figure 6C). The authors proposed that the $\left[\mathrm{PPh}_{3} \mathrm{Au}\right]^{+}$catalyst has a dual role during the course of the reaction. First, the gold(I)-complex activates the alkyne group to facilitate a 1,3-acyloxy migration leading to the allene intermediates 68. Further along into the mechanistic pathway, the metal acts as Lewis acid promoting the intramolecular Ferrier reaction with the departure of the alcoxy group, which is integrated as a new ligand in the gold complex $[\mathrm{Au}] \mathrm{OR}^{2}$ furnishing the oxocarbenium species 69. Lastly the bicyclic structure of $\mathbf{7 0}$ is formed by cyclization and formation of $\mathrm{AcOR}^{2}$ as a by-product (Liao et al., 2017).

In conjunction with the latter works, functionalized anthracenes 73 can also be generated under thermal conditions $\left(50^{\circ} \mathrm{C}\right)$ with bulky gold(I)-catalysts promoting the cyclization of 2-(2-ethynylbenzyl)furan featuring propargyl carbonate or ester groups 71. Intermediates $\mathbf{7 2}$ are proposed to be formed after a 3,3-rearrangement of the propargyl carboxylate $\mathrm{OR}^{2}$ moiety, and then evolve to products 73 via a $[4+2]-$ cycloaddition between the furanyl system and the distal $\mathrm{C}=\mathrm{C}$ double bond of the allene. A similar protocol was applied in the cycloisoimerization of the related 1,5-furan-ynes 74 to obtain 


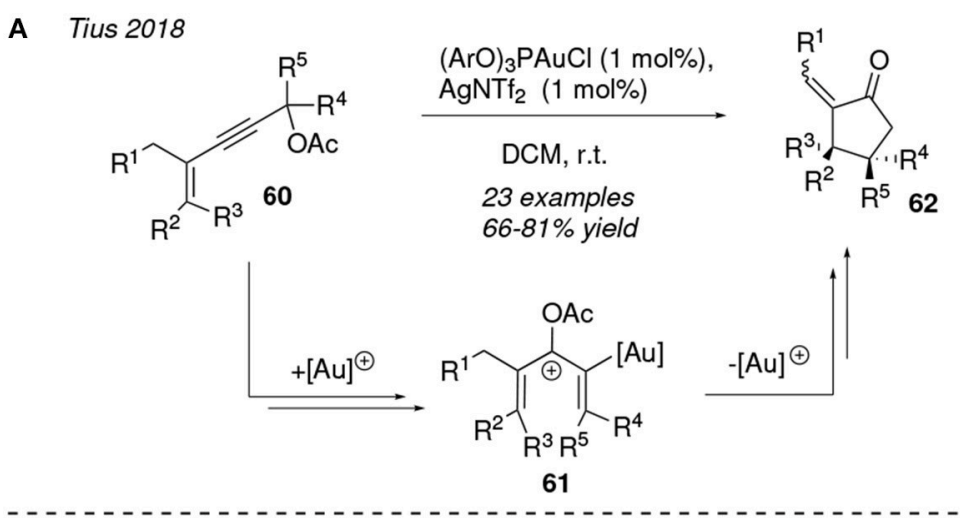

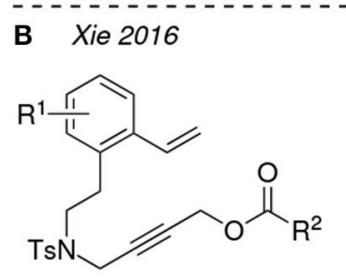

63

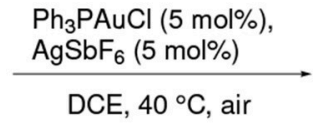

10 examples $55-82 \%$ yield

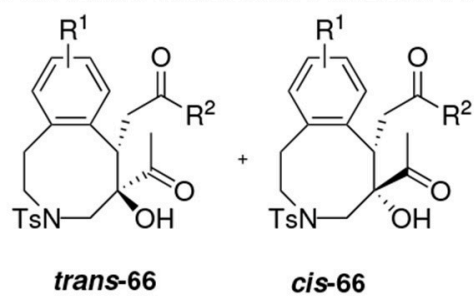<smiles>C=CC</smiles>

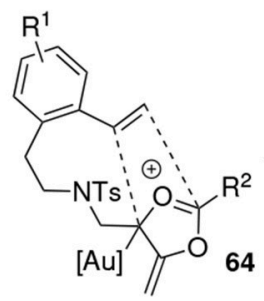
$-[\mathrm{Au}]^{\oplus}$
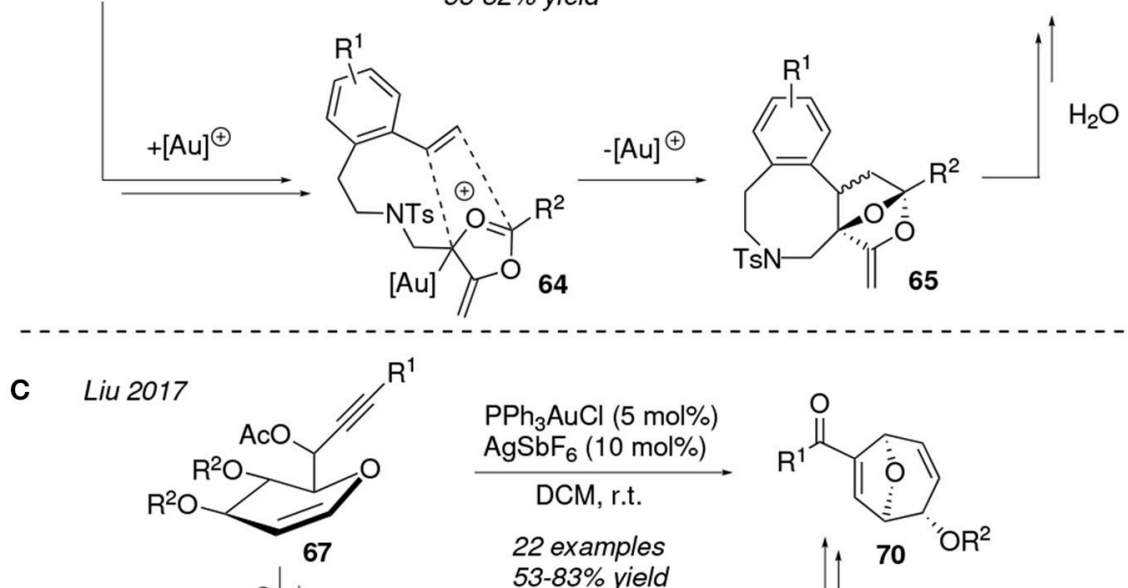<smiles>O=C1CCCC1</smiles>

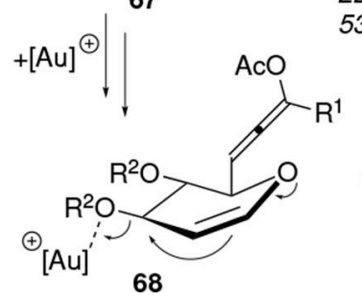

\section{2 examples} $53-83 \%$ yield

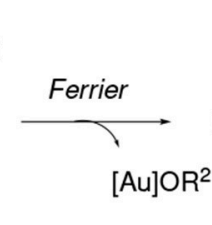

$[\mathrm{Au}] \mathrm{OR} \mathrm{R}^{2}$

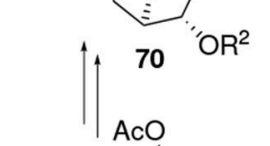

FIGURE 6 | Gold-mediated cycloisomerization of $1, n$-dieniynes started by an acyloxy shift process.

antracen-1(2H)ones 75 ; in this case a late $1,2-\mathrm{R}^{1}$ shift is required after the $[4+2]$-cycloaddition step to afford the final ketone (Figure 7A) (Sun et al., 2016).

An unusual chemoselective gold-activation of alkenes over allenes using sterically bulky ligands as $\mathrm{di}^{t} \mathrm{BuXphos}$ has been described by Shi et al. Substituted bicyclic[4.4.0]dihydronaphthalenes $\mathbf{7 8}$ were accessed from the dienynes 76 through an initial 1,3-OPiv rearrangement and subsequent alkene-activation at intermediate 77 , which then experiments an allene-ene cyclization and hydrolysis. Interestingly, the pivaloyl group (Piv) migrates selectively during the formation of hydrobenzopyranes $(\mathbf{7 8}, \mathrm{X}=\mathrm{O})$ as indicated in Figure 7B (Thummanapelli et al., 2016).

As in the case of $1, n$-enynes, reactions initiated by migration of a carbonate or ester group have been subject of study in related 1,n-diyne derivatives (Day and Chan, 2016; Li et al., 2017a). Chan et al. reported in two different studies the gold(I)-mediated cycloisomerization of 1-en-4,n-enynes 79 (Chen et al., 2016a) and 1-en-3,9-enynes 81 (Figure 8A) (Rao et al., 2016). Both reactions were conducted under the same solvent and temperature conditions (DCE, $80^{\circ} \mathrm{C}$ ) but with different gold catalysts. Thus, for the conversion 


\section{A Liu 2016}<smiles>CCCC(O)C#Cc1ccccc1Cc1ccc(C)o1</smiles>

71
[tBuXphosAu(MeCN)]SbF 6 (5 mol\%)

DCE, $50^{\circ} \mathrm{C}$

13 examples

$50-96 \%$ yield

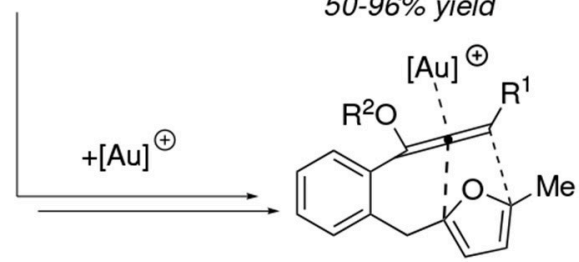<smiles>[R]c1c(C)ccc2cc3ccccc3c(OCC)c12</smiles>

73

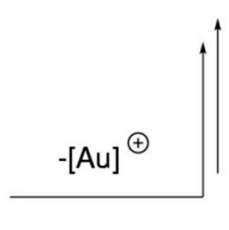

72<smiles>[R]C#CC(O[R])c1ccccc1Cc1ccc(P)o1</smiles>

74

[tBuXphosAu(MeCN)]SbF 6 (5 mol\%)

or

tBuXphosAuCl/AgOTf (5 mol\%)

DCE, $50^{\circ} \mathrm{C}$<smiles>[R]C1([R])C=Cc2cc3ccccc3cc2C1=O</smiles>

12 examples $42-88 \%$ yield

75

B Shi 2016<smiles>[R]C#CC(O[NH2+])c1ccccc1[X]</smiles>

76, $\mathrm{X}=\mathrm{CH}_{2}, \mathrm{O}, \mathrm{NTs}$
ditBuXphosAunTf 2 (2 mol\%)

Toluene, $\mathrm{H}_{2} \mathrm{O}, 50^{\circ} \mathrm{C}$

\section{4 examples} $56-90 \%$ yield

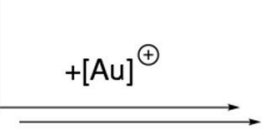<smiles>[X]c1ccccc1C=C(CC(=C)C)C([R])([R])OCC</smiles>

$\left[A^{\prime} u\right] \oplus$

FIGURE 7 | Gold-mediated cycloisomerization of $1, n$-dienynes started by an acyloxy shift process.

$79 \rightarrow \mathbf{8 0}\left[\right.$ JohnPhosAuNCMe ${ }^{+}$was the active cationic gold species which provided the best results, whereas in the case of the cycloisomerization of the diyne $\mathbf{8 1}[\mathrm{LAuCHPh}]^{+}$was employed. In the latter, therefore a cationic catalyst featuring a $N$-heterocyclic carbene ligand is used. In both cases the mechanistic route would be initiated by the gold-activation of the propargyl moiety promoting a 1,3-acyloxy transfer followed by several cyclizations. In fact, the relative position of the olefine moiety determines whether the evolution of the mechanisms at the first cyclization occurs through either a 1,4-eneallene cycloisometization toward $\mathbf{8 0}$ or a metallo-Nazarov cyclization toward the tetracycles 82. In 2018, the synthesis of naphtho[2,3c]furan-1(3-H)-ones $\mathbf{8 4}$ was reported via cycloisomerization of propargylic ynoates 83, under thermal conditions with
BrettPhosAuCl as catalyst and in presence of $\mathrm{NaBAr}_{4}^{F}$ as an activator of the gold complex (Figure 8B) (Li et al., 2018a). The reaction mechanism would involve a [3,3]-rearrangement of the propargyl ester leading to a carboxyallene intermediate followed by an intramolecular Diels-Alder cyclization. The authors were able to synthesize up to 24 examples of $\mathbf{8 4}$ combining diverse alkyl and aryl substituents and they also describe a new method for the in-situ generation of carboxyallene intermediates.

An interesting formation of primitive dendrimer systems containing bicyclic structures from substrates incorporating two sets of dialkynes were described by $\mathrm{Oh}$ et al. The hydrated $\mathrm{NaAuCl}_{4}$ mediates in the thermal cycloisomerization of 85 trough a dual 1,3- and 1,2-acyloxy transposition at the terminal and inner alkyne moieties, respectively, followed by 


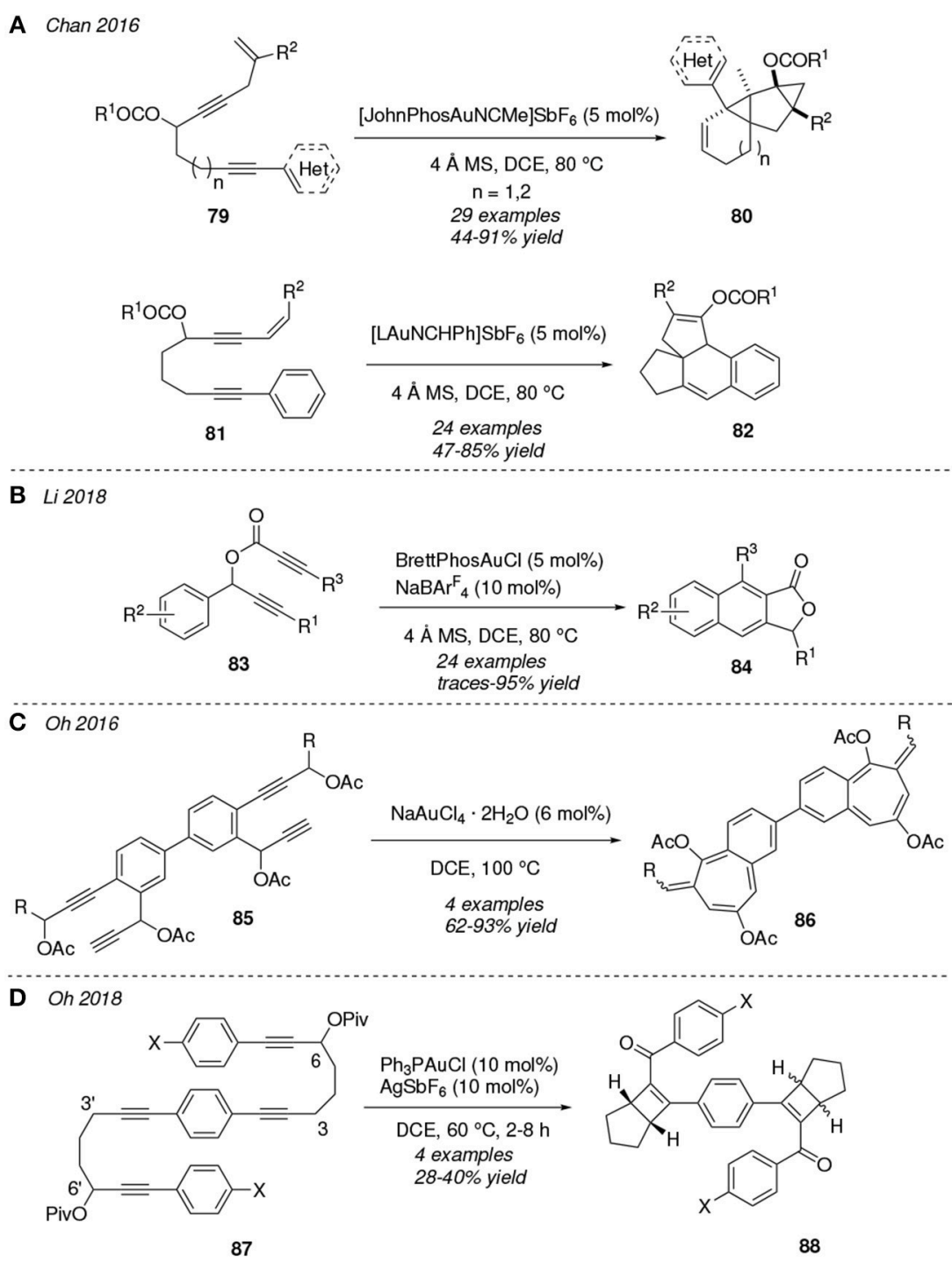

FIGURE 8 | Gold-mediated cycloisomerization of 1,n-diynes started by an acyloxy shift process.

an annulation process leading to the benzo-fused 7 -member cycles 86 (Figure 8C) (Lee et al., 2016). In a related work, the $\left[\mathrm{Ph}_{3} \mathrm{PAu}\right]^{+}$-activation of propargyl ester motifs promotes the 1,3-acyl shift/[2+2]/hydrolysis cascade reaction of the diynes $\mathbf{8 7}$ furnishing a diastereomeric mixture of the polycyclic systems $\mathbf{8 8}$ (Figure 8D). The authors were able to resolve the diasteromeric mixture and even extend this protocol to other diynes in which the pivaloate substituents are located at positions 3 and 3 ' (Lee et al., 2018).

\subsection{Gold-Catalyzed Cycloisomerization Processes of $1, n$-enynes and 1,n-diynes Initiated by a Nucleophilic Attack Onto the Alkyne Group}

Gold is able to activate an alkyne group toward a nucleophilic addition and, for instance, make it susceptible to act as the receptor motif in a hydride shift reaction (Xie et al., 2014; Nahide et al., 2018). In this sense, Wong et al. reported the goldalkyne activation of 1,5-enynes $\mathbf{8 1}$ toward a rare 1,6-hydride shift leading to the gold-activated oxonium intermediate 90, which then experiments a Prins-type cascade forming two new $\mathrm{C}-\mathrm{C}$ bonds and furnishing the final tricyclic system 91 (Figure 9A) (Lu et al., 2018). This mechanistic proposal is supported by deuterium-labeling cross-over experiments. According to the authors, there is no precedent of cycloisomerizations initiated by a gold-catalyzed 1,6-hydride transfer reaction. This protocol provides rapid access to fused polycyclic compounds presented in many bioactive natural products as Nominine or Walsuranin B.

An activated alkyne group could act as electrophile in an intramolecular nucleophilic attack if a functional group present within the system has such nature. An experimental gold(I)mediated double 6-endo cascade cyclization strategy of enynes 


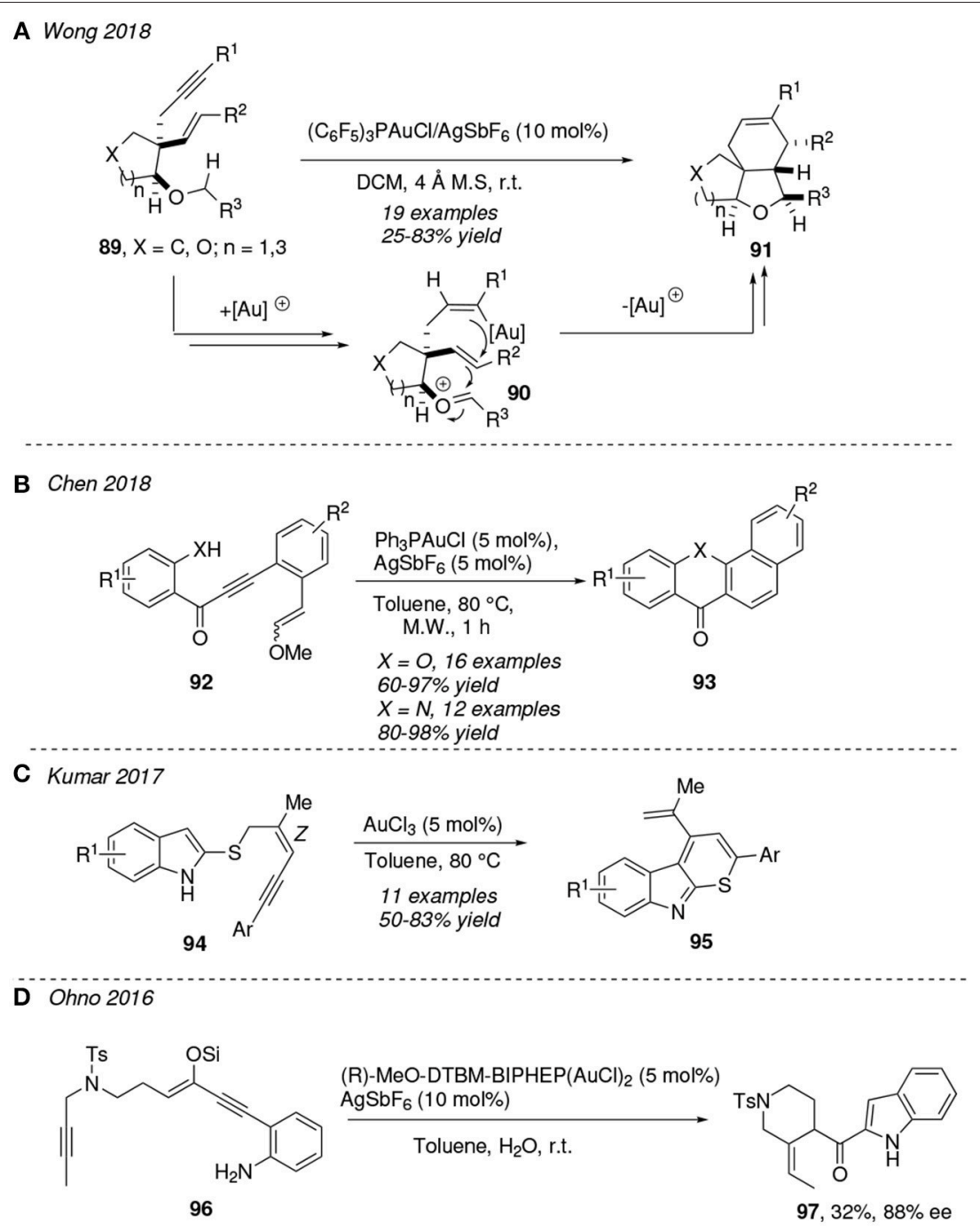

FIGURE 9 | Gold-mediated cycloisomerization reactions of 1,n-enynes containing an internal atom-centered nucleophile.

92 to form benzoxanthenone and benzoacridone derivatives 93 has been described by Cheng et al. (Figure 9B). The tandem process starts with an $\mathrm{X}$-attack $(\mathrm{X}=\mathrm{O}, \mathrm{N})$ to the alkyne moiety and further carbocyclization involving the pendant alkene motif, ending with the formation of both $\mathrm{C}-\mathrm{N}$ and $\mathrm{C}-\mathrm{C}$ bonds and releasing a methanol molecule. This reaction is conducted in toluene at $80^{\circ} \mathrm{C}$ under microwave irradiation; this provides a better yield when compared with conventional thermal treatment (Xiong et al., 2018). Before this study, the same group had reported a similar protocol to obtain benzo[a]carbazoles via gold(I)-mediated cycloisomerization of structurally related ortho-alkynylanilines in toluene at $100^{\circ} \mathrm{C}$ (Peng et al., 2017). Likewise, gold(III)-complexes have been reported to be excellent catalysts in similar transformations. Kumar et al. developed an elegant gold(III)-mediated strategy for the synthesis of substituted thiopyrano[2,3-b]indoles 95. This implies that enyne tethered indole sulfides $\mathbf{9 4}$ undergo a tandem $\sigma$-bond migration/6-endo-trig cyclization/oxidative aromatization process. The authors highlight the significance of the $Z$ orientation of the $\mathrm{C}=\mathrm{C}$ bond to assist the rearrangement step (Figure 9C) (Jha et al., 2017).

Besides, the use of bimetallic complexes has become more popular in gold chemistry during the last years (El Sayed Moussa et al., 2016; Trommenschlager et al., 2017; Arif et al., 2018). The synthesis of the (+)-conolidine alkaloid has been reported via a gold(I)-catalyzed cascade cyclization of the conjugated enyne 96. The bulky bimetalic gold complex (R)-MeO-DTBM-BIPHEP $(\mathrm{AuCl})_{2}$ bearing a chiral ligand is used as effective precatalyst to form the ketone intermediate 97 (32\% yield and $88 \%$ ee) (Figure 9D) (Naoe et al., 2016). Recently, $\mathrm{Zi}$ et al. achieved the first desymmetrization of prochiral bisphenols via gold(I)-catalyzed enantioselective hydroetherification of alkynes. This protocol was applied successfully in (di)alkyne compounds bearing P-stereogenic 
A Zhu 2017

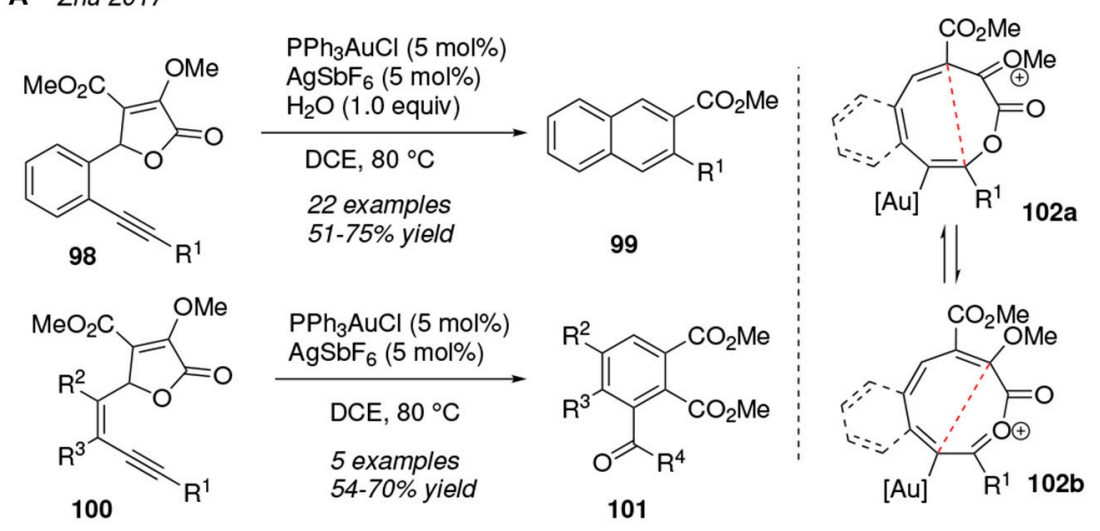

B Zhu 2018<smiles>[R]C(C#CBr)=C([R])C1OC(=O)C(OC)=C1F</smiles>

SIPrAuCl (5 mol\%) $\mathrm{AgBF}_{4}(5 \mathrm{~mol} \%)$

DCE, $100^{\circ} \mathrm{C}$ 25 examples $45-91 \%$ yield $\mathrm{E}=\mathrm{CO}_{2} \mathrm{Me}$

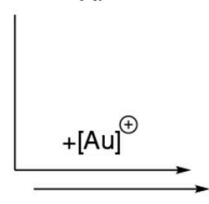

$\mathrm{O}$

$\mathrm{R}^{2}$
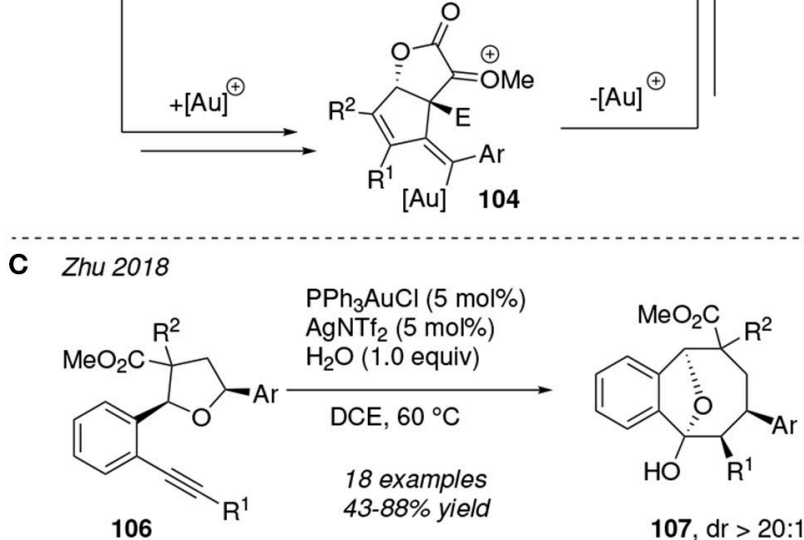

FIGURE 10 | Gold-mediated cycloisomerization of enyne-lactones.

centers using the bimetallic chiral precatalyst (S)-DTBMSegphos $(\mathrm{AuCl})_{2}$ (Zheng et al., 2018).

Several reports pivoting about cycloisomerization reactions of enyne-lactones by gold(I)-catalysis have been published by Zhu et al. (Figure 10). Under $\left[\mathrm{Ph}_{3} \mathrm{PAu}\right]^{+}$catalysis, the lactoneenynes $\mathbf{9 8}$ and $\mathbf{1 0 0}$ are proposed to experiment a ring-expansion reaction of the lactone ring affording the previously unknown 2oxoninium intermediate 102a which exists in equilibrium with 102b. The presence of the benzo-fused ring at intermediates 102 displaces the equilibrium reaction toward the most stable 2-oxoninium 102a, whereas, in its absence, intermediate $\mathbf{1 0 2} \mathbf{b}$ is the preferred product. Both intermediates 102a and 102b then undergo an interesting $6 \pi$ electrocyclization reaction and subsequent aromatization process toward compounds 99 and 101, respectively. The addition of one equivalent of water is required for the formation of $\mathbf{9 9}$ whereas the diester $\mathbf{1 0 1}$ is isolated even in anhydrous media (Figure 10A) (Luo et al., 2017). On the other hand, the nature of the ligand at the gold(I)-catalyst seems to have a high influence in the evolution of the mechanism allowing the transformation of related enyne-lactones 103. Thus, benzo-fused polycyclic compounds $\mathbf{1 0 5}$ are achieved using a carbene derivate gold complex as precatalyst ( $\mathrm{SIPrAuCl}$ ) in presence of the activating partner $\mathrm{AgBF}_{4}$ (Figure 10B). The authors reasoned that an initial vinyl ether addition onto the activated-alkyne toward the $\mathbf{1 0 4}$ motif might be favored rather than an oxygen attack, as in the previous transformations, mostly due to the strong $\sigma$-donor and weak $\pi$-acceptor nature of the SIPr ligated gold center (Luo et al., 2018). If the lactone motif is replaced by a tetrahydrofuran group as in compound 106, then the bicyclo $\mathbf{1 0 7}$ is obtained via a gold(I)-catalyzed 5-exo$\mathrm{dig} /[1,3]$ O-to-C tandem process in a diastereoselective fashion (Figure 10C) (Zhang et al., 2018a). With this set of papers Zhu 
et al. demonstrated the versatility of diverse gold(I) complexes in the ring-expansion process of lactones and related structural motifs via a nucleophilic attack onto an activated alkyne group.

$1, n$-Diynes are prone to be transformed into valuable heterocyclic systems through the attack of an internal nucleophile, in particular - $\mathrm{NH},-\mathrm{CO}$, or $-\mathrm{OH}$ groups, when present, either onto one or both of the gold $\pi$-activated $\mathrm{C}-\mathrm{C}$ triple bonds. Lamellarins are a group of pyrrole alkaloids based in a pyrano[3,4- $b]$ pyrrol-7(1H)-one scaffold which present anticancer activity. Thibonett et al. designed a gold(I)catalyzed cycloisomerization of the 1,4-diynes 108 furnishing the substituted pyrano-pyrrol-ones 109 via two consecutive intramolecular 5-endo-dig and 6-endo-dig additions to both activated alkyne motifs (Figure 11A). The former cyclization proceeds involving the amine group in the formation of the pyrrol ring, whereas in the latter it is one of the ester groups who is involved in the formation of the pyranone ring (Delaye et al., 2017).

In 2017, Xu et al. reported an elegant gold(I)-catalyzed cyclization/carbonylation cascade reaction of diynes containing an amide group which operates under mild reaction conditions. Thus, 1,6-diynes 110 undergo a 6-exo-dig cyclization with the carbonyl oxygen of the amide group leading to the 1,3oxazine gold intermediate 111, which is then intercepted by the remaining alkyne affording the intermediate 112. After protodeauration and hydration $\beta, \gamma$-unsaturated ketones 113 are obtained in good yields (Figure 11B) (Bao et al., 2017). Otherwise, 1,6-diynes bearing ortho-benzyl alcohols 114 evolve to dihydroisobenzofuran derivatives 116 trough a gold(I)catalyzed protocol initiated by two consecutive unsual 5-exo-dig hydroxyalkilation processes and a further Prins-like cyclization. Authors reasoned the formation of the 5-exo-dig cyclized product taking into account the more favorable six-membered ring chelated gold complex 115 when compared to the alternative bigger chelate, which would result in a more usual 6-endo-Ocyclization (Figure 11C) (Hashmi et al., 2007). This kind of transformation has not only been described as regioselective but also as stereoselective at the spiro-quaternary center placing the oxygen atom in the axial disposition (Cao et al., 2016).

Chan et al. designed an efficient method to prepare azacycle-fused pyrroles 121-123 by gold(I)-catalyzed dehydrative cycloisomerization of $\beta$-amino- $1, n$-diynols 117 . The mechanistic sequence would be initiated with the formation of the pyrrole ring (118) promoted by the nucleophilic attack of the pendant amine toward the closer gold-activated alkyne and departure of a water molecule. A subsequent gold activation of the remaining alkyne motif would promote a cyclization leading to the intermediates $\mathbf{1 1 9}$ and $\mathbf{1 2 0}$. The type of cyclization depends on both the length of the alkyl chain and the nature of the $\mathrm{X}$ linker $\left(\mathrm{X}=-\mathrm{NTs}, \mathrm{O}\right.$ or $\left.\mathrm{CH}_{2}\right)$, as is shown in Figure 11D. Furthermore, the intermediate $\mathbf{1 1 9}$ is the precursor of the fused pyrroles 121 and 122 whereas pyrroles 123 result from the expansion and further protodeauration of $\mathbf{1 2 0}$ (Kothandaraman et al., 2016). The nature of the substituents of the amide groups at the diynes $\mathbf{1 2 4}$ direct the gold(I)-catalyzed formation of the lactams 125 and 126. Thus, for a bulky $\mathrm{R}^{4}$ group and an electronrich migrating $\mathrm{R}^{3}$ group path $a$ is more favorable and involves a tandem $N R^{3}$-nucleophilic cyclization $/ 1,3-\mathrm{R}^{3}$ migration/1,5enyne cycloisomerization process to yield 125 . In contrast, if $\mathrm{R}^{3}$ is a poor shifting group, the dienynes $\mathbf{1 2 4}$ evolve trough a cascade hydroamination/Michael addition reaction (path $b$ ) to afford the spirocycle 126 (Figure 11E) (Li et al., 2018b).

\subsection{Gold-Catalyzed Carbocyclization Processes of $1, n$-enynes and 1,n-diynes}

Those processes in which $1, n$-enyne substrates are transformed into isomeric products trough an initial carbocyclization step are very well documented. In 2018, Percy et al. have shown for the first time the intramolecular carbocyclization of difluorinated enol acetals bearing a pendant unsaturated group 127 leading to the cyclohexanone scaffolds $\mathbf{1 2 8}$ in a moderate diastereoisomeric ratio (Figure 12A). The reaction is conducted in a mixture of dichloromethane and methanol solvents at $40{ }^{\circ} \mathrm{C}$ in presence of $\mathrm{IPrAuCl}$ as precatalyst and $\mathrm{AgSbF}_{6}$ acting as activator agent of the previous one. The carbonyl group is further reduced to obtain difluorinated diols. Besides, a mixture of difluorinated pyran scaffolds $\mathbf{1 3 0}$ and $\mathbf{1 3 1}$ are isolated, the gemdiol derivate $\mathbf{1 3 1}$ being the major product when using propargyl ethers 129 as starting reactants and 2-MeTHF as solvent (McCarter et al., 2018).

In a very recent publication, Echavarren et al. reported the gold(I)-catalyzed cascade cyclization reaction of oxime-tethered 1,6-enynes 132 furnishing the substituted oxazines $(n=1)$ and dihydroisoxazoles $(n=0) 133$ in a diastereospecific fashion and very good yields (Figure 12B). The mechanism ruling this transformation has been proposed to proceed stepwise through an intramolecular addition of the $\mathrm{O}$ atom of the oxime onto the transient gold-carbene intermediate, as revealed by the DFT computations performed. The $Z$ orientation at the $\mathrm{C}=\mathrm{N}$ bond of the oxime group is determining to obtain 133, otherwise, with the $E$-oxime variant, dihydropyrrole $N$-oxides are isolated. The latter substrates resulted from the initial $N$-attack of the oxime over the gold-carbene intermediate (Muratore et al., 2018).

The use of gold-homogeneus catalysis to achieve complex poly-annulated-cyclic systems is also gaining attention as, for instance, in the formation of the biologically active compound (+)-aureol (Wildermuth et al., 2016). In this sense, stable functionalized hydroacenes $\mathbf{1 3 5}$ are easily accessible up to nine rings trough a gold(I)-catalyzed cyclization of aryl-tethered 1,7enynes 134, under mild reaction conditions (Figure 12C). A great number of different substituents $\mathrm{R}^{1}$ and $\mathrm{R}^{2}$ decorating the aryl motifs or even fused aromatic rings are compatible with the conditions, revealing the high synthethic value of this protocol (Dorel et al., 2016).

In 2016, Sanz et al. demonstrated that $\beta, \beta$-diaryl-o-(alkynyl)styrenes 136 are transformed at $80{ }^{\circ} \mathrm{C}$ into dihydroindeno[2,1a] indenes 137 under gold(I)-catalysis whereas benzofulvenes 138 are obtained at $0{ }^{\circ} \mathrm{C}$. The formation of the tetracycles 137 implies a formal $[4+1]$ cycloaddition trough a tandem 5-endocyclization-diene/iso-Nazarov cyclization process (Figure 12D) (Sanjuán et al., 2016). A computational study for related gold(I)mediated transformations in which the initial styrenes bear alkyl groups at the $\beta$ positions has been reported by Zhou et al. 


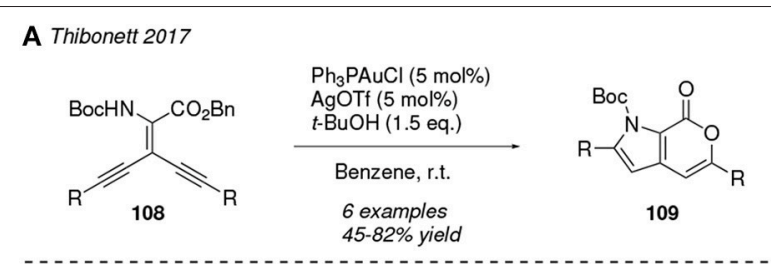

B $X u 2017$

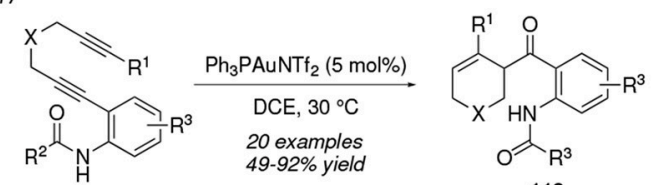

110, $X=N T s, ~ O$
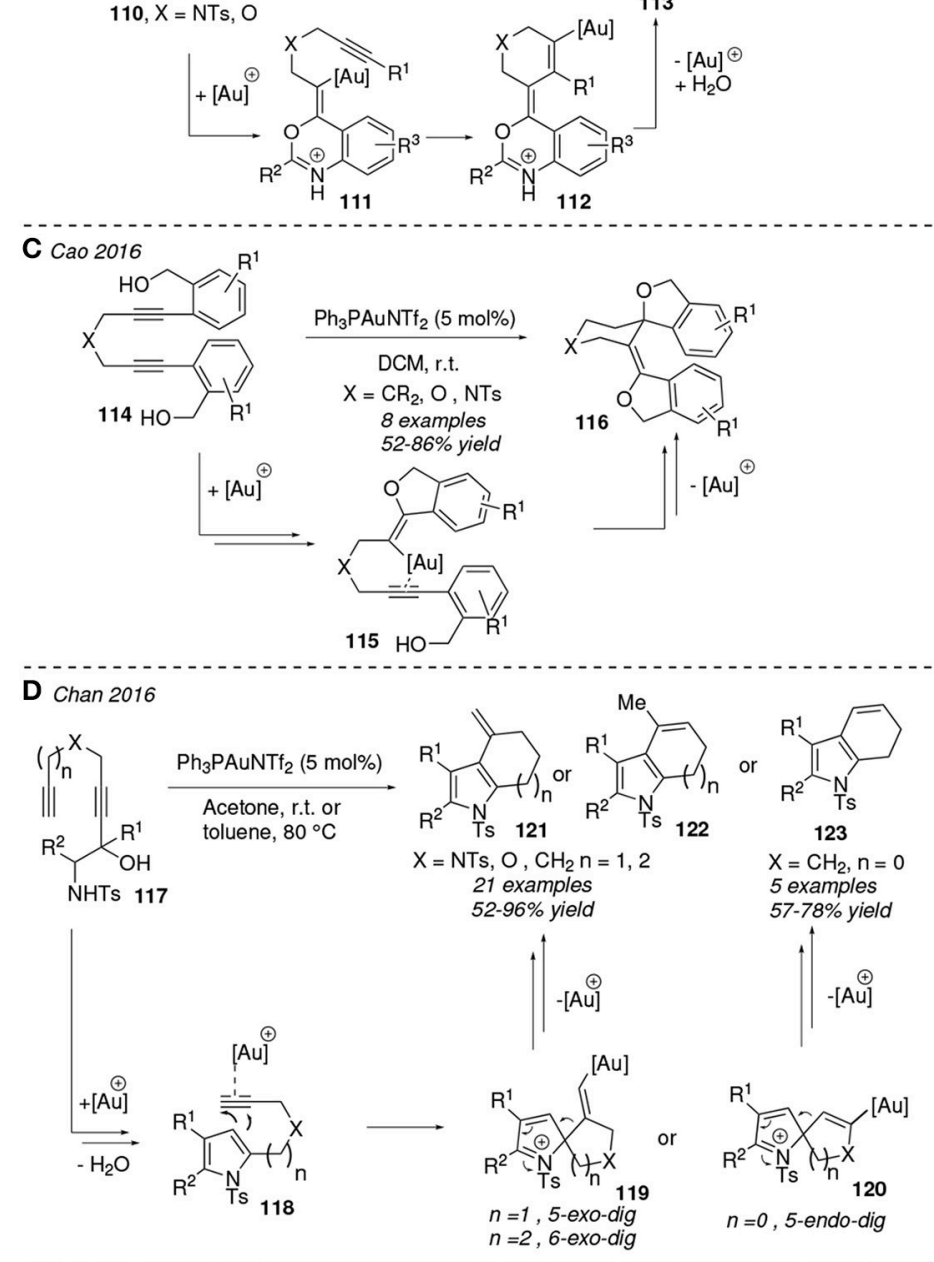

E Van der Eycken 2018

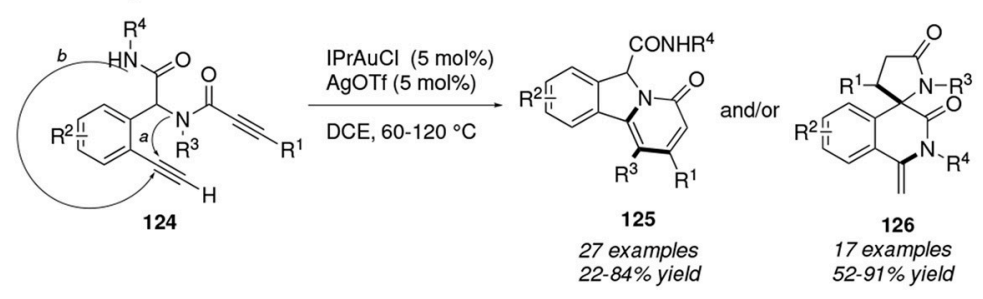

FIGURE 11 | Gold-mediated cycloisomerization of 1,n-diynes containing an internal atom-centered nucleophile. 


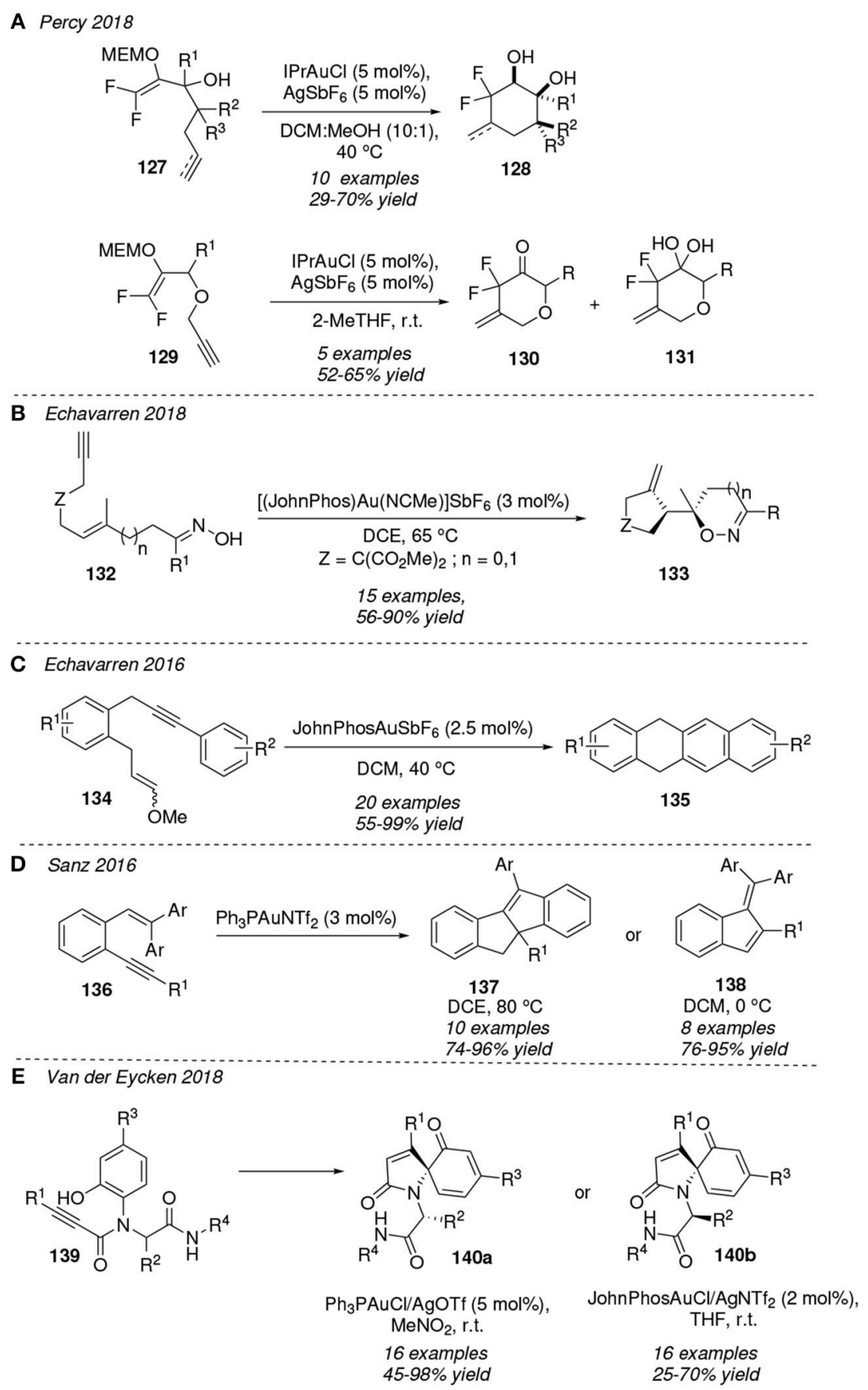

FIGURE 12 | Gold-mediated cycloisomerization of 1,n-enynes.

(2018b) The authors concluded that the reaction would evolve trough a $[1,2]-\mathrm{H}$ shift on the isopropyl moiety rather than a cyclopropane expansion, as suggested in the experimental work (Sanjuán et al., 2015).

The Van der Eycken research group has reported the elegant one-pot synthesis of spirocyclic pyrrol-2-one-dienones 140 via a gold(I)-catalyzed intramolecular Friedel-Craft reaction of the Ugi adducts 139 (Figure 12E). Two diastereomeric dienones were isolated depending on both the gold-catalyst and the reaction conditions. Taking the $\mathbf{1 4 0}$ yields into account and supported by a conformational theoretical analysis, the authors concluded that the isomer 140a resulting from the catalytic treatment with $\mathrm{Ph}_{3} \mathrm{PAuCl}$ is energetically more favorable than that derived from the bulkier JhonPhosAuCl precatalyst (140b) (Nechaev et al., 
2018). A related work had been previously published by the same group (He et al., 2017).

Continuing with carbocyclization processes, it was reported that several $\operatorname{gold}(\mathrm{I})$ salts $\left(\mathrm{L}=\mathrm{t}-\mathrm{Bu}{ }_{3} \mathrm{P}, \mathrm{IPr} ; \mathrm{X}=[\mathrm{OTf}]-,\left[\mathrm{NTf}_{2}\right]^{-}\right.$, $\left[\mathrm{SbF}_{6}\right]^{-}$) activate the 1,5-enynes $\mathbf{1 4 1}$ toward gold-allenes 142 via a [3,3]-rearrangement. The subsequent tandem Nazarov cyclization/[1,2]-H shift process allows the formation of the fused cyclopentadienes 143, which were exposed to a further reduction to obtain primary alcohols $\mathbf{1 4 4}$ (Figure 13A). The position of the two double bonds at the final cyclopentadiene ring strongly depends on the size and type of the fused cycle, mostly carbocycles and $N$-heterocycles (Rinaldi et al., 2018). Bandini et al. described a related $[3,3]$-sigmatropic rearrangement for the site-selective gold(I)mediated dearomatization of napthylpropynol derivatives toward dihydrofurylnaphthalen-2(1H)-ones (An et al., 2017).

In 2018, Nakamura et al. published the gold(I)-catalyzed intramolecular $S_{E} A r$ reaction of isoxazoles 145 substituted by a propargyl amine or ether at $\mathrm{C} 4$ position. This cycloisomerization furnishes the fused isoxazolo substrates $\mathbf{1 4 6}$ in good yields at $60^{\circ} \mathrm{C}$ (Figure 13B). Moreover, the authors demonstrated that the addition of an external hydride acceptor as $\mathrm{N}$ phenylbenzaldimine increased the yield in the synthesis of isoxazolopyridines (146, $\mathrm{X}=\mathrm{NH}$ ). Remarkably, the use of bulky gold(I)-complexes, such as [JhonPhosAu] ${ }^{+}$, is essential for the satisfactory formation of products (Morita et al., 2018).

Gold-catalyzed cyclizations in 1,6-enynes on indole scaffolds have also been reported in the last years (Pérez-Galán et al., 2016). Figure 13C shows a recent example in which $N$ substituted indoles 147 containing an alkene-tethered diyne cycloisomerize to eight-membered ring indoziline derivatives 148 under gold(I)-catalysis. Shi et al. described the use of bulkyphosphine gold complexes to promote, under thermal treatment $\left(80^{\circ} \mathrm{C}\right)$, two intramolecular nucleophilic attacks at the $\mathrm{C} 2$ and C3 centers of the indole moiety of both activated internal alkyne groups. Interestingly, compounds 148 exhibit yellowgreen fluorescence, so they may have potential applications in the field of OLEDs (Liu et al., 2018). Related gold(I)mediated carbocyclizations of enynes involving an eightmembered ring formation have been described recently in the synthesis of dibenzo[b,e][1,4]diazocines (Ito et al., 2018). Likewise, gold(III) complexes have been reported to be able to promote carbocyclization processes. Thus, bis(indoyl)methyl alkynols 149 are transformed into substituted carbazoles 150 under catalysis of hydratated $\mathrm{NaAuCl}_{4}$ (Figure 13D). The mechanism for this transformation was found computationally to proceed via an unsual 1,2-migration of an indolylmethyl moiety as key step (Suárez et al., 2017). 1,2- And 1,3-quinazolinone fused pyrroles 152 and 154 were achieved involving a $\mathrm{AuCl}_{3}-$ mediated cycloisomerization of alkynyl pyrroles 151 and 153 (Figure 13E). 1,2-Quinazolinones 152 are formed via an initial $1,3-\mathrm{R}^{3}$ rearrangement followed by a 6-exo-trig cyclization involving the pendant pyrrol ring at 151, while 153 is transformed into $\mathbf{1 5 4}$ directly through a 6-exo-dig cyclization onto the terminal akyne unit (Wei et al., 2018). Nevertheless, related structurally pyrroles bearing a non-terminal akyne experiments a 7-endo-dig cyclization rather than a 6-exo-dig (Kong et al., 2018).

Reactants containing a cyclopropane unit have gained considerable attention lately, and a number of remarkable transformations using this kind of substrates have been achieved through gold-chemistry. The cis-to-trans isomerization of cyclopropane rings has been experimental and computationally studied under gold(I) and gold(III) catalysis, concluding that chiral bisoxazoline- $\mathrm{Au}(\mathrm{III})$ complexes are the best catalysts for promoting this isomerization (Reiersølmoen et al., 2018).

Shi and co-workers reported a set of works on gold(I)-catalyzed cycloisomerization of enynes containing methylenecyclopropanes. The $\operatorname{IPrAuSbF}_{6}$ catalyst is able to activate the alkyne motif of enynes toward an intramolecular cyclization and further ring expansion of the methylenecyclopropane scaffold. For instance, aniline-linked 1,6-enynes bearing a cyclopropane ring 155 can be converted into 1,2-dihydroquinolines $\mathbf{1 5 6}$ and $\mathbf{1 5 7}$ under thermal conditions in a solution of dichloroethane. Under gold-catalysis, products 156, containing a cyclobutene ring were the major product compared to compounds 157 , in which the cyclopropane is not expanded (Figure 14A). This product ratio is inverted when using $\mathrm{AgSbF}_{6}$ as catalyst (Jiang et al., 2018). This methodology was extended to methylenecyclopropane-contained ynamides 158. Thus, substrates 158 evolve at room temperature to the polycyclic system 159 using $\mathrm{Ph}_{3} \mathrm{PAuCl}$ as catalyst whereas spirocyclics 160 were obtained by using a more sterically bulky catalyst, such as JohnphosAuCl. In both cases the gold-catalyst promotes the expansion of the alkylidencyclopropane to a four-member ring but only in the latter the catalyst facilities the subsequent intramolecular Friedel-Crafts process in the formation of $\mathbf{1 6 0}$ (Figure 14B) (Zhang et al., 2018b). A similar situation is reported for the intramolecular hydroarylation of the enynes $\mathbf{1 6 1}$ toward oxacycles 162 and 163 . Thus, whereas both catalysts, $\mathrm{IPrAuSbF}_{6}$ and $\left(p-\mathrm{CF}_{3} \mathrm{C}_{6} \mathrm{H}_{4}\right)_{3} \mathrm{PAuSbF}_{6}$, promote the carbocyclization step, only the former promotes the methylenecyclopropane expansion to a cyclobutene ring (Figure 14C). The authors reasoned this different reactivity attending to the inability of the gold complex containing electron-deficient phosphine ligands to activate the alkene moiety toward the ring expansion process (Fang et al., 2016). Temperature can also be a determining factor in these reactions, as shown in the isomerization of 1,5-enynes containing a cyclopropane ring, 164. These systems cycloisomerize to related bicyclic or spirobicyclic compounds depending on the catalyst and the thermal conditions. For instance, 164 furnishes 165 in presence of $\mathrm{IPrAuNTf}_{2}$ at $-30^{\circ} \mathrm{C}$. However, substrate 164 is converted into the biscyclopropanes 166 at $0^{\circ} \mathrm{C}$ under catalysis of the bulky gold complex [JohnPhosAu(MeCN)] $\mathrm{SbF}_{6}$ whereas bicycles 167 can be obtained at $60^{\circ} \mathrm{C}$ in a good diastereoisomeric ratio (Figure 14D). The authors proposed a catalytic cycle in which compounds $\mathbf{1 6 5}$ and $\mathbf{1 6 6}$ are precursors of $\mathbf{1 6 7}$ (Chen et al., 2016b). In the same line, Voituriez et al. described the enantioselective synthesis of cyclobutanone derivatives 169 via gold(I)-catalyzed cycloisomerization of enyne-methylenecyclopropanes 168. The most broadly tested catalyst was a binuclear gold complex bearing a bulky 


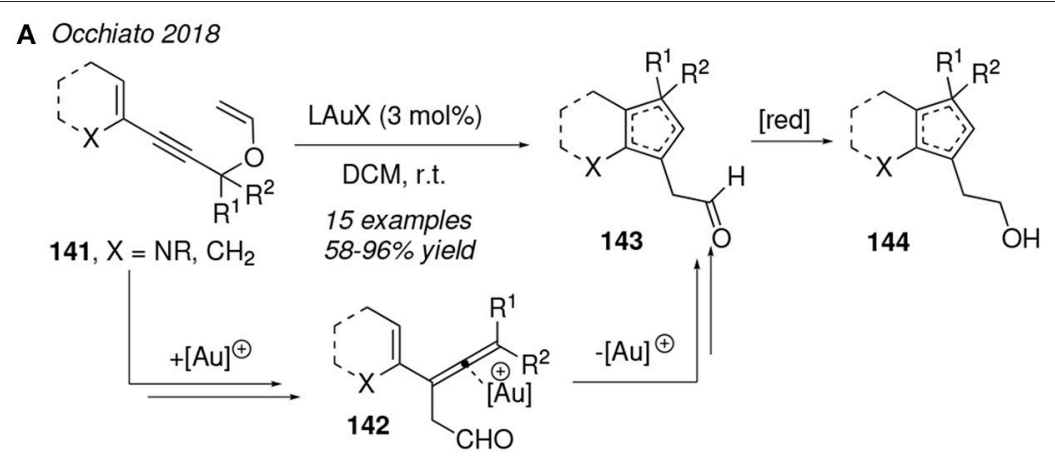

B Nakamura 2018

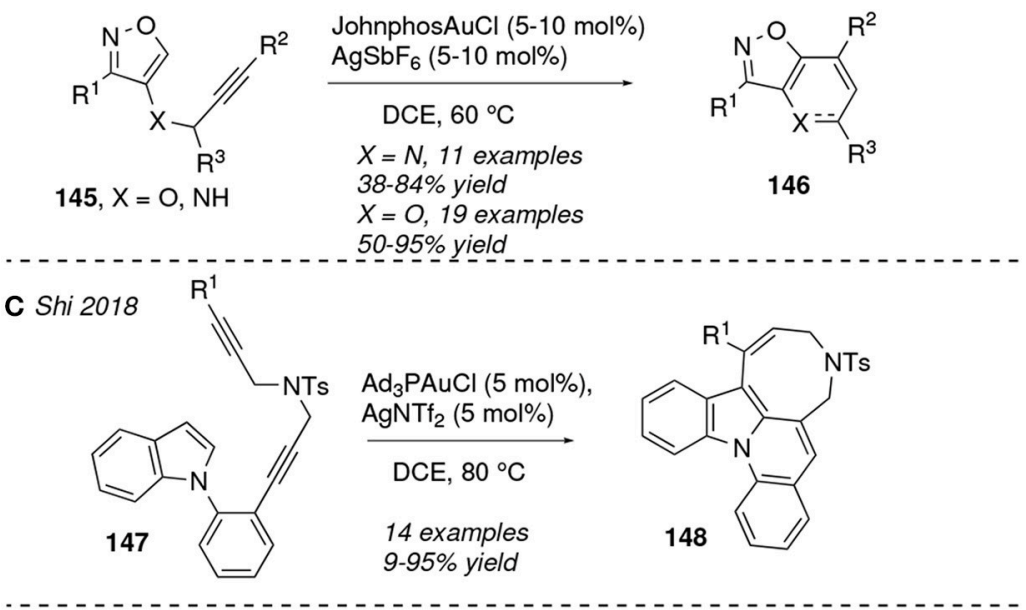

D Sanz 2017
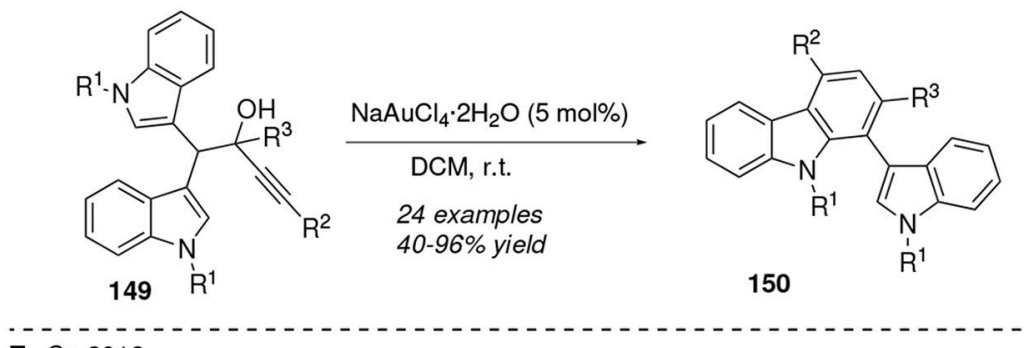

E Su 2018
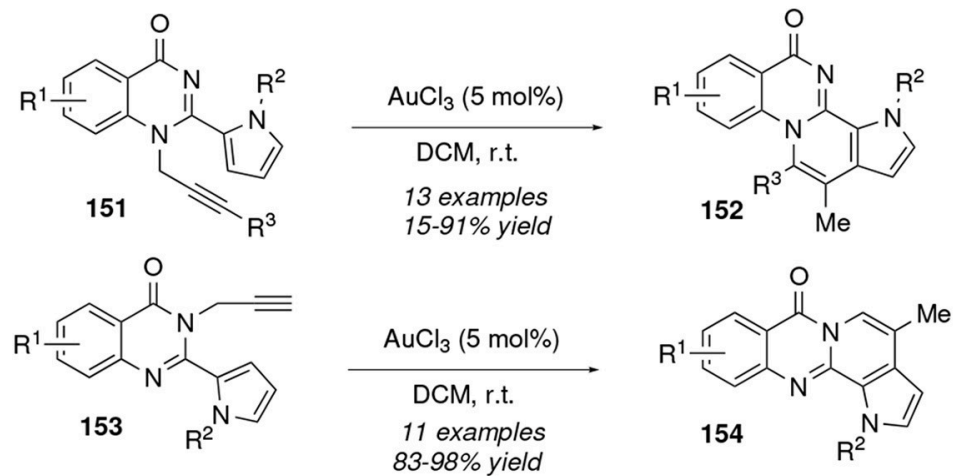

FIGURE 13 | Gold-mediated cycloisomerization of 1,n-enynes. 

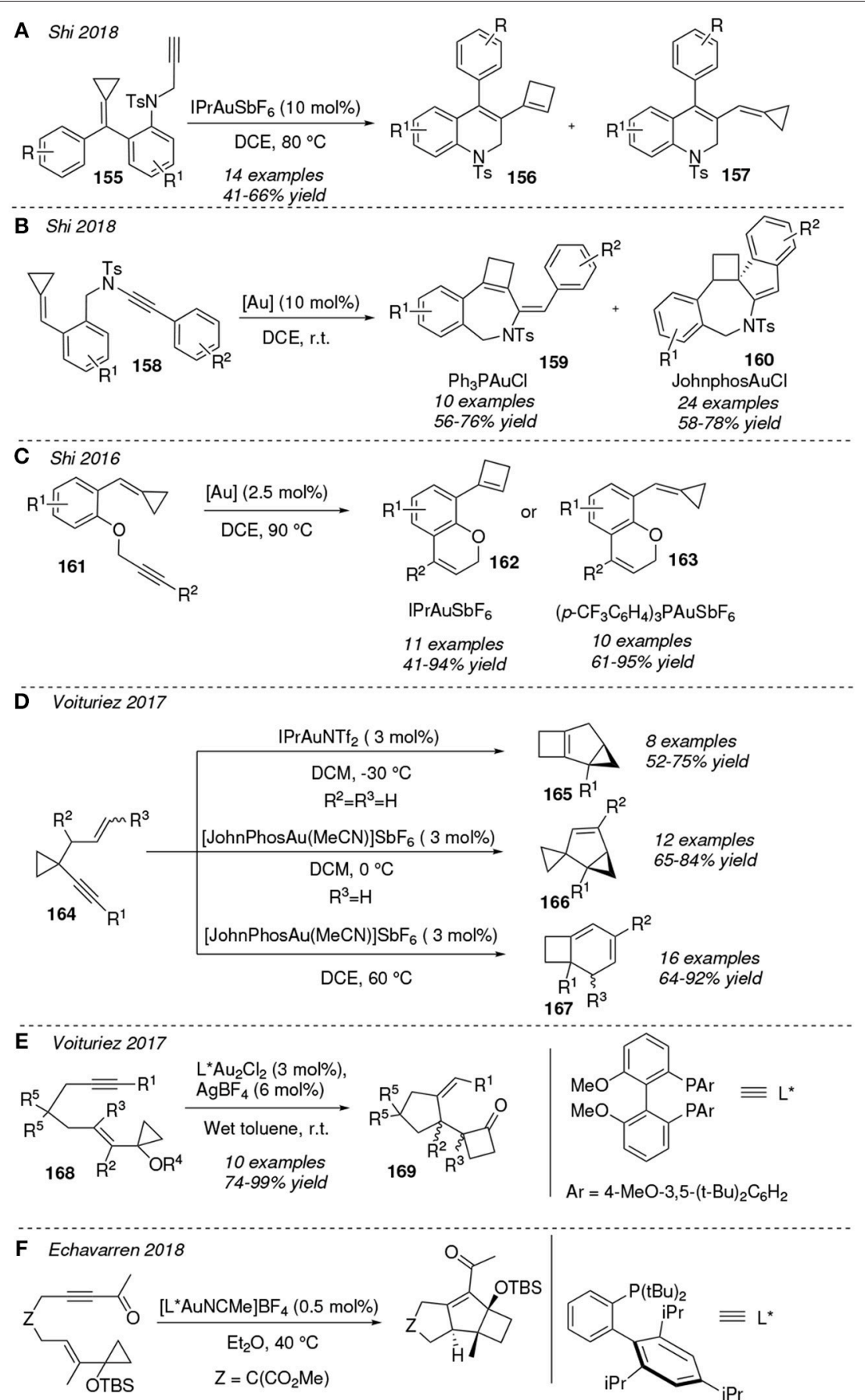

170

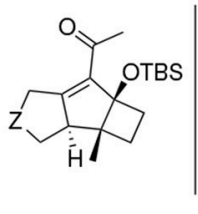

$171,72 \%$ yield

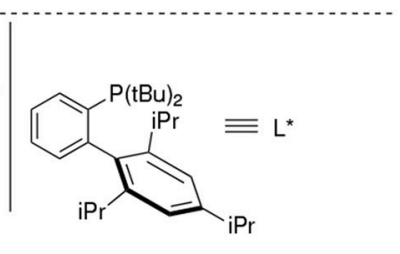

FIGURE 14 | Gold-mediated cycloisomerization of 1,n-dienynes containing a cyclopropane ring.

chiral-phosphine ligand, as represented in Figure 14E. The major isolated products are those with substituents $R^{2}$ and $\mathrm{R}^{3}$ presenting cis configuration ( $\mathrm{Wu}$ et al., 2017). A similar approach was used as the key step in the total synthesis of the sesquiterpene Repraesentin F. Echavarren et al. reported a highly diastereoselective gold(I)-mediated cyclization of the 1,6enyne $\mathbf{1 7 0}$ via a tandem cycloisomerization/Prins-type reaction furnishing the tricyclic systems $\mathbf{1 7 1}$ containing the unsual skeleton of this natural product. Through this protocol the diasteroisomer with the desired anti ring fusion configuration 

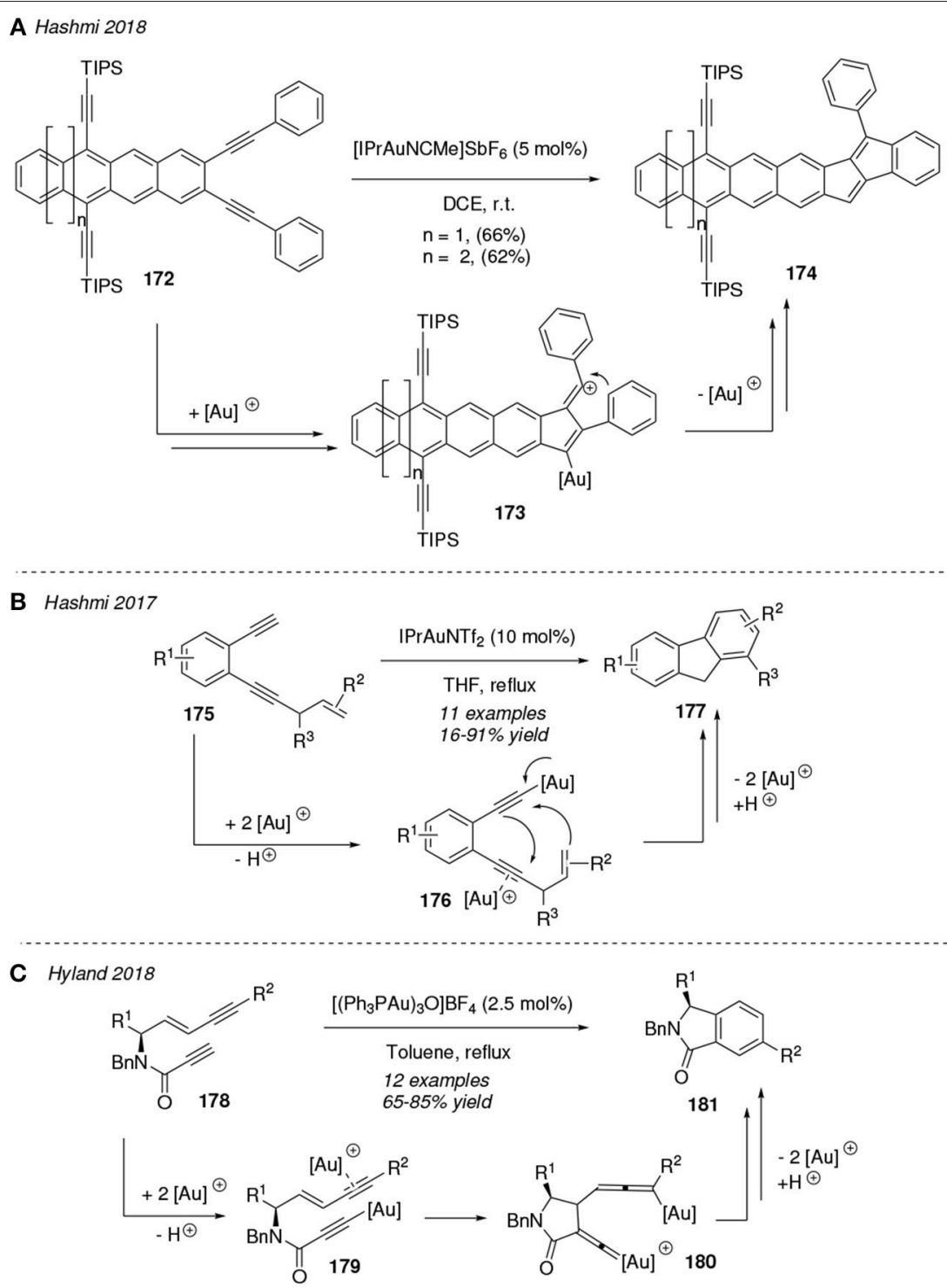

FIGURE 15 | Gold-mediated cycloisomerization reactions of $1, n$-diynes.

is obtained as major product in a 7.2:1 ratio with respect to that with the syn fusion (Figure 14F) (Ferrer and Echavarren, 2018b).

The reactivity pattern of $1, n$-diynes has also been smartly exploited toward the construction of complex highly $\pi$ conjugated polycyclic systems (Asiri and Hashmi, 2016). In this sense, the works from Hashmi stand out with several remarkable publications on this topic in the last years (Tšupova et al., 2017; Wurm et al., 2017, 2018). A representative example is shown in Figure 15A. They described the gold-mediated cycloisomerization of 1,5-diynes building on an aromatic ring 172 toward aromatic polycyclic-annulated systems 174 . The reaction mechanism involves a vinyl cation intermediate $\mathbf{1 7 3}$ and operates under mild reaction conditions. Interestingly optical properties have been described in this kind of annulatedpentalene compounds making them potential candidates for future optoelectronic devices (Sekine et al., 2018). Another example by Hashmi et al. was reported in 2017 and was highlighted as the first intramolecular trapping of dually goldactivated intermediates $\mathbf{1 7 6}$ with an olefinic $\mathrm{C}\left(\mathrm{sp}^{2}\right)-\mathrm{H}$ bond (Figure 15B). 1,5-Diynes bearing an allyl-substituted alkene attached to an aromatic skeleton (175) could also be converted into fluorene derivatives $\mathbf{1 7 7}$ via a dehydrogenative dual goldcatalyzed activation at reflux of tetrahydrofuran (Bucher et al., 2017). In this sense, dual-gold catalysis has been implemented in the cycloaromatization of unconjugated $(E)$-enedynes $\mathbf{1 7 8}$ toward isoindolines $\mathbf{1 8 1}$ by using the trigold oxo complex $\left[\left(\mathrm{Ph}_{3} \mathrm{PAu}\right)_{3} \mathrm{O}\right] \mathrm{BF}_{4}$ as catalyst (Figure 15C). Both specific experiments with deuterated reactants and a detailed theoretical study indicate that the most feasible mechanistic pathway is that involving the very reactive allenyl-gold/gold-vinylidene 
intermediate 180, which is generated from a dualgold activated substrate $\mathbf{1 7 9}$ via a 5-exo-trig cyclization. The subsequent carbocyclization and rearomatization afforded the enantioriched isoindolines $\mathbf{1 8 1}$ in good yields (Zamani et al., 2019).

\section{CONCLUSIONS}

In this review, the interest on gold and its relevance in intramolecular isomerization reactions is confirmed by taking into account the vast number of studied reported in the last 3 years and covered here. Most of the isomerization processes included in this review are initiated by three main different kind of transformations at allene and alkyne sites: nucleophilick attack onto the activated alkyne, 1,3 or 1,2 - rearrangement of a carbonate/ester group over the $\pi$ system or a carbocyclization process. As we have shown, structurally complex molecules can be synthesize from easily reachable reactants under gold-catalysis and mild reaction conditions. Fewer in number but still important, some studies have developed gold(III)-catalysts although gold(I)-complexes seem to be more versatile, effective and preferred in this kind of reactions. Nowadays, enantioselective synthesis is a paramount goal, particularly when chemists are involved in

\section{REFERENCES}

Alcaide, B., Almendros, P., Cembellín, S., Fernández, I., and Martínez del Campo, T. (2016). Metal-catalyzed cyclization reactions of 2,3,4-Trien-1-ols: a joint experimental-computational study. Chem. A Eur. J. 22, 11667-11676. doi: 10.1002/chem.201601838

Alcaide, B., Almendros, P., Fernández, I., Herrera, F., and Luna, A. (2018). Gold-catalyzed divergent ring-closing modes of indole-tethered amino allenynes. Chem. Eur. J. 24, 1448-1454. doi: 10.1002/chem. 201705294

An, J., Parodi, A., Monari, M., Reis, M. C., Lopez, C. S., and Bandini, M. (2017). Gold-catalyzed dearomatization of 2-naphthols with alkynes. Chem. Eur. J. 23, 17473-17477. doi: 10.1002/chem.201704942

Arif, T., Cazorla, C., Bogliotti, N., Saleh, N., Blanchard, F., Gandon, V., et al. (2018). Bimetallic gold(i) complexes of photoswitchable phosphines: synthesis and uses in cooperative catalysis. Catal. Sci. Technol. 8, 710-715. doi: 10.1039/ c7cy01614j

Asiri, A. M., and Hashmi, A. S. K. (2016). Gold-catalysed reactions of diynes. Chem. Soc. Rev. 45, 4471-4503. doi: 10.1039/c6cs00023a

Aubert, C., Fensterbank, L., Garcia, P., Malacria, M., and Simonneau, A. (2011). Transition metal catalyzed cycloisomerizations of $1, \mathrm{n}$-allenynes and-allenenes. Chem. Rev. 111, 1954-1993. doi: 10.1021/cr100376w

Bao, M., Lu, W., Cai, Y., Qiu, L., and Xu, X. (2017). Gold(I)catalyzed cyclization/carbonylation cascade reaction of 1,6-diynes: an access to $\beta, \gamma$-unsaturated ketones. J. Org. Chem. 82, 13386-13395. doi: 10.1021/acs.joc.7b02461

Belmont, P., and Parker, E. (2009). Silver and gold catalysis for cycloisomerization reactions. Eur. J. Org. Chem. 2009, 6075-6089. doi: 10.1002/ejoc.200900790

Blons, C., Amgoune, A., and Bourissou, D. (2018). Gold(III) $\pi$ complexes. Dalt. Trans. 47, 10388-10393. doi: 10.1039/c8dt01457d

Bucher, J., Wurm, T., Taschinski, S., Sachs, E., Ascough, D., Rudolph, M., et al. (2017). Dual gold catalysis: synthesis of fluorene derivatives from diynes. Adv. Synth. Catal. 359, 225-233. doi: 10.1002/adsc.201600987

Cao, Z., Li, S., Li, J., Meng, X., Zhang, H., Sun, X., et al. (2016). Gold-catalyzed $\pi$-directed regioselective cyclization of bis(: $\mathrm{O}$-alkynyl benzyl alcohols): rapid access to dihydroisobenzofuran derivatives. New J. Chem. 40, 8211-8215. doi: 10.1039/c6nj02066f biologically relevant molecules. Accordingly, the number of studies involving gold-complexes containing chiral ligands is growing notably. Although we can consider gold as a "young" metal, chemically speaking, it is clear that this metal center has many advantages to take into account when designing and performing innovative, complexity oriented and efficient chemical transformations.

\section{AUTHOR CONTRIBUTIONS}

CS, ON, and MM-L contributed conception of the review article, scope and structure. MM-L drafted the article. CS and ON revised its scientific and formal content.

\section{FUNDING}

This work has been funded by the Ministerio de Economía, Industria y Competitividad (CTQ2016-75023-C2-2P) and the Xunta de Galicia (ED431C 2017/27).

\section{ACKNOWLEDGMENTS}

MM-L thanks Xunta de Galicia for a post-doctoral research contract (ED481B 2016/166-0).

Chen, C., Zou, Y., Chen, X., Zhang, X., Rao, W., and Chan, P. W. H. (2016a). Gold-catalyzed tandem 1,3-migration/double cyclopropanation of 1-Ene-4,ndiyne esters to tetracyclodecene and tetracycloundecene derivatives. Org. Lett. 18, 4730-4733. doi: 10.1021/acs.orglett.6b02404

Chen, G. Q., Fang, W., Wei, Y., Tang, X. Y., and Shi, M. (2016b). Divergent reaction pathways in gold-catalyzed cycloisomerization of 1,5-enynes containing a cyclopropane ring: dramatic: ortho substituent and temperature effects. Chem. Sci. 7, 4318-4328. doi: 10.1039/c6sc00058d

Chen, X., Merrett, J. T., and Hong Chan, P. W. (2018). Gold-catalyzed formal $[4+2]$ cycloaddition of 5-(Ethynylamino)pent-2-yn-1-yl Esters to 1,2,3,5-tetrahydrobenzo [g] quinolines. Org. Lett. 20, 1542-1545. doi: 10.1021/acs.orglett.8b00267

Cheong, P. H. Y., Morganelli, P., Luzung, M. R., Houk, K. N., and Toste, F. D. (2008). Gold-catalyzed cycloisomerization of 1,5-allenynes via dual activation of an ene reaction. J. Am. Chem. Soc. 130, 4517-4526. doi: 10.1021/ja711058f

Ciancaleoni, G., Belpassi, L., Zuccaccia, D., Tarantelli, F., and Belanzoni, P. (2015). Counterion effect in the reaction mechanism of nhc gold(i)-catalyzed alkoxylation of alkynes: computational insight into experiment. ACS Catal. 5, 803-814. doi: 10.1021/cs501681f

Congmon, J., and Tius, M. A. (2018). Contiguous quaternary centers from a Au I -catalyzed nazarov cyclization. Eur. J. Org. Chem. 2018, 2926-2930. doi: 10.1002/ejoc.201800604

Das, A., Hua, Y., Yousufuddin, M., Cundari, T. R., Jeon, J., and Dias, H. V. (2016). Gold-mediated isomerization of cyclooctyne to ring fused olefinic bicycles. Eur. J. Inorg. Chem. 2016, 995-1001. doi: 10.1002/ejic.201600021

Day, D. P., and Chan, P. W. H. (2016). Gold-catalyzed cycloisomerizations of 1,n-diyne carbonates and esters. Adv. Synth. Catal. 358, 1368-1384. doi: 10.1002/adsc.201600005

Delaye, P. O., Petrignet, J., Thiery, E., and Thibonnet, J. (2017). Gold-silver catalyzed straightforward one pot synthesis of pyrano[3,4-: B] pyrrol-7(1 H)ones. Org. Biomol. Chem. 15, 7290-7295. doi: 10.1039/c7ob01849e

Dorel, R., and Echavarren, A. M. (2015). Gold(I)-catalyzed activation of alkynes for the construction of molecular complexity. Chem. Rev. 115, 9028-9072. doi: $10.1021 / \mathrm{cr} 500691 \mathrm{k}$

Dorel, R., McGonigal, P. R., and Echavarren, A. M. (2016). Hydroacenes made easy by gold(I) catalysis. Angew. Chem. - Int. Ed. 55, 11120-11123. doi: 10.1002/anie.201604952 
Ebule, R. E., Malhotra, D., Hammond, G. B., and Xu, B. (2016). Ligand effects in the gold catalyzed hydration of alkynes. Adv. Synth. Catal. 358, 1478-1481. doi: $10.1002 /$ adsc. 201501079

El Sayed Moussa, M., Chen, H., Wang, Z., Srebro-Hooper, M., Vanthuyne, N., Chevance, S., et al. (2016). Bimetallic Gold(I) complexes with ethynylhelicene and bis-phosphole ligands: understanding the role of aurophilic interactions in their chiroptical properties. Chem. Eur. J. 22, 6075-6086. doi: 10.1002/chem.201600126

Fang, W., Tang, X. Y., and Shi, M. (2016). Gold(i)-catalyzed intramolecular hydroarylation and the subsequent ring enlargement of methylenecyclopropanes to cyclobutenes. RSC Adv. 6, 40474-40479. doi: $10.1039 / \mathrm{c} 6 \mathrm{ra} 02549 \mathrm{~h}$

Faza, O. N., and López, C. S. (2015). Computational Approaches to Homogeneous Gold Catalysis. London: Springer International Publishing. doi: 10.1007/128_2014_591

Feng, S., Wang, Z., Zhang, W., Xie, X., and She, X. (2016). An efficient synthesis of benzazocines by gold(I)-catalyzed tandem 1,2-acyloxy shift/[3+2] cycloaddition of terminal 1,9-enynyl esters. Chem. An Asian J. 11, 2167-2172. doi: 10.1002/asia.201600593

Fensterbank, L., and Malacria, M. (2014). Molecular complexity from polyunsaturated substrates: the gold catalysis approach. Acc. Chem. Res. 47, 953-965. doi: 10.1021/ar4002334

Ferrer, S., and Echavarren, A. M. (2018a). Role of $\sigma, \pi$-Digold(I) alkyne complexes in reactions of enynes. Organometallics 37, 781-786. doi: 10.1021/acs.organomet.7b00668

Ferrer, S., and Echavarren, A. M. (2018b). Total synthesis of repraesentin F and configuration reassignment by a gold(I)-catalyzed cyclization cascade. Org. Lett. 20, 5784-5788. doi: 10.1021/acs.orglett.8b02478

Fukuda, Y., and Utimoto, K. (1991). Effective transformation of unactivated alkynes into ketones or acetals with a gold(iii) catalyst. J. Org. Chem. 56, 3729-3731. doi: 10.1021/jo00011a058

García-Morales, C., and Echavarren, A. (2018). From straightforward gold(I)catalyzed enyne cyclizations to more demanding intermolecular reactions of alkynes with alkenes. Synlett 29, 2225-2237. doi: 10.1055/s-0037-1610203

Gatto, M., Baratta, W., Belanzoni, P., Zotto, A. D., Tarantelli, F., and Zuccaccia, D. (2018). Hydration and alkoxylation of alkynes catalyzed by NHC-Au-OTf. Green. Chem. 20, 2125-2134 doi: 10.1039/c8gc00508g

Gatto, M., Belanzoni, P., Belpassi, L., Biasiolo, L., Del Zotto, A., Tarantelli, F., et al. (2016). Solvent-, silver-, and acid-free NHC-Au-X catalyzed hydration of alkynes. The pivotal role of the counterion. ACS Catal. 6, 7363-7376. doi: 10.1021/acscatal.6b01626

Ghosh, A., Basak, A., Chakrabarty, K., Ghosh, B., and Das, G. K. (2014). Ligandassisted acyl migration in au-catalyzed isomerization of propargylic ester to diketone: a DFT study. J. Org. Chem. 79, 5652-5663. doi: 10.1021/jo500822v

Gobé, V., Dousset, M., Retailleau, P., Gandon, V., and Guinchard, X. (2018). Dissecting the gold(I)-catalyzed carboaminations of N-Allyl tetrahydro- $\beta$ carbolines to allenes. J. Org. Chem. 83, 898-912. doi: 10.1021/acs.joc.7b02900

Gorin, D. J., and Toste, F. D. (2007). Relativistic effects in homogeneous gold catalysis. Nature 446, 395-403. doi: 10.1038/nature05592

Gung, B. W., Holmes, M. R., Jones, C. A., Ma, R., and Barnes, C. L. (2016). Structure-enantioselectivity correlation in nhc-au(i) catalysis for 1,6-enynecyclizations. Tetrahedron Lett. 57, 3912-3915. doi: 10.1016/j.tetlet.2016.07.046

Hashmi, A. S., Frost, T. M., and Bats, J. W. (2000). Highly selective goldcatalyzed arene synthesis [24]. J. Am. Chem. Soc. 122, 11553-11554. doi: $10.1021 /$ ja005570d

Hashmi, A. S. K. (2014). Dual gold catalysis. Acc. Chem. Res. 47, 864-876. doi: $10.1021 /$ ar500015k

Hashmi, A. S. K., Schäfer, S., Wölfle, M., Gil, C. D., Fischer, P., Laguna, A., et al. (2007). Gold-catalyzed benzylic C-H activation at room temperature. Angew. Chem. Int. Ed. 46, 6184-6187. doi: 10.1002/anie.200701521

He, Y., Li, Z., Tian, G., Song, L., Van Meervelt, L., and Van der Eycken, E. V. (2017). Gold-catalyzed diastereoselective domino dearomatization/ipsocyclization/aza-Michael sequence: a facile access to diverse fused azaspiro tetracyclic scaffolds. Chem. Commun. 53, 6413-6416. doi: $10.1039 /$ C7CC03152A

Herndon, J. W. (2018). The chemistry of the carbon-transition metal double and triple bond: Annual survey covering the year 2017. Coord. Chem. Rev. 377, 86-190. doi: 10.1016/j.ccr.2018.08.007
Homs, A., Obradors, C., Leboeuf, D., and Echavarren, A. M. (2014). Dissecting anion effects in gold(I)-catalyzed intermolecular cycloadditions. Adv. Synth. Catal. 356, 221-228. doi: 10.1002/adsc.201300704

Hu, Y., Bai, M., Yang, Y., and Zhou, Q. (2017). Metal-catalyzed enyne cycloisomerization in natural product total synthesis. Org. Chem. Front. 4, 2256-2275. doi: 10.1039/c7qo00702g

Ito, M., Inoue, D., Takaki, A., Kanyiva, K. S., and Shibata, T. (2018). 8-exo-digSelective Cycloisomerization for the Synthesis of Dibenzo[b,e][1,4]diazocines Using Cationic AuI Catalysts. Eur. J. Org. Chem. 2018, 4740-4747. doi: $10.1002 /$ ejoc.201801037

Jha, M., Dhiman, S., Cameron, T. S., Kumar, D., and Kumar, A. (2017). Au-catalyzed synthesis of thiopyrano[2,3-b]indoles featuring tandem rearrangement and hydroarylation. Org. Lett. 19, 2038-2041. doi: 10.1021/acs.orglett.7b00617

Jia, M., and Bandini, M. (2015). Counterion effects in homogeneous gold catalysis. ACS Catal. 5, 1638-1652. doi: 10.1021/cs501902v

Jiang, B., Wei, Y., and Shi, M. (2018). Gold- and silver-catalyzed intramolecular annulation and rearrangement of aniline-linked 1,6-enynes containing methylenecyclopropanes. Org. Chem. Front. 5, 2091-2097. doi: $10.1039 / \mathrm{C} 8 \mathrm{QO} 00358 \mathrm{~K}$

Jiménez-Núñez, E. and Echavarren, A. M. (2008). Gold-catalyzed cycloisomerizations of enynes: a mechanistic perspective. Chem. Rev. 108, 3326-3350. doi: $10.1021 / \mathrm{cr} 0684319$

Jones, A. C. (2015). Gold $\pi$-Complexes as Model Intermediates in Gold Catalysis. Cham: Springer International Publishing.

Kiriakidi, S., Nieto Faza, O., Kolocouris, A., and López, C. S. (2017). Governing effects in the mechanism of the gold-catalyzed cycloisomerization of allenic hydroxylamine derivatives. Org. Biomol. Chem. 15, 5920-5926. doi: 10.1039/c7ob01275f

Kong, X. F., Zhan, F., He, G. X., Pan, C. X., Gu, C. X., Lu, K., et al. (2018). Goldcatalyzed selective 6-exo-dig and 7-endo-dig cyclizations of alkyn-tethered indoles to prepare rutaecarpine derivatives. J. Org. Chem. 83, 2006-2017. doi: 10.1021/acs.joc.7b02956

Kothandaraman, P., Zhao, Y., Lee, B. R., Le Ng, C. J., Lee, J. Y., Ayers, B. J., et al. (2016). Gold-catalyzed aminoalkenylation of $\beta$-Amino-1,n-diynols to cycloalkyl-, piperidinyl- and pyranyl-fused pyrroles. Adv. Synth. Catal. 358, 1385-1391. doi: 10.1002/adsc.201600011

Larsen, M. H., Houk, K. N., and Hashmi, A. S. K. (2015). Dual gold catalysis: stepwise catalyst transfer via dinuclear clusters. J. Am. Chem. Soc. 137, 10668 10676. doi: 10.1021/jacs.5b05773

Lee, K. H., Jillella, R., Kim, J., and Oh, C. H. (2018). Synthesis of primitive dendrimer systems bearing bicyclo[3,2,0]Hept-6-en-6-yl groups via unique Au-catalyzed [2+2] cyclization. Bull. Korean Chem. Soc. 39, 651-656. doi: $10.1002 /$ bkcs. 11445

Lee, Y.-C., and Kumar, K. (2018). Gold(I) catalyzed enyne cycloisomerization - a roadmap to privileged heterocyclic scaffolds. Isr. J. Chem. 58, 531-556. doi: $10.1002 /$ ijch.201700067

Lee, Y. J., Heo, H. G., and Oh, C. H. (2016). Syntheses of 2,2'bibenzo[7]annulenes by double au-catalyzed sequential activation of propargylic carboxylates. Tetrahedron 72, 6113-6117. doi: 10.1016/j.tet.2016. 07.060

Lempke, L., Sak, H., Kubicki, M., and Krause, N. (2016). Gold-catalyzed cycloisomerization of trifluoromethylated allenols: sustainability and mechanistic studies. Org. Chem. Front. 3, 1514-1519. doi: 10.1039/c6qo00423g

Li, H., Harris, R. J., Nakafuku, K., and Widenhoefer, R. A. (2016). Kinetics and mechanism of allene racemization catalyzed by a gold N-heterocyclic carbene complex. Organometallics 35, 2242-2248. doi: 10.1021/acs.organomet. $6 \mathrm{~b} 00307$

Li, T., Wang, H., Qian, P., Yang, Y., Li, B., and Zhang, L. (2018a), $\mathrm{Au}(\mathrm{I})$-Catalyzed expeditious access to naphtho[2,3-c] furan-1(3-H)-ones from readily available propargylic ynoates. Chem. Commun. 54, 10447-10450. doi: $10.1039 / \mathrm{C} 8 \mathrm{CC} 06056 \mathrm{H}$

Li, Y., Kirillov, A. M., Fang, R., and Yang, L. (2017a). Effect of substituent on the mechanism and chemoselectivity of the gold(I)-catalyzed propargyl ester tandem cyclization. Organometallics 36, 1164-1172. doi: 10.1021/acs.organomet.7b00042

Li, Y., Wei, M., and Dai, M. (2017b). Gold catalysis-facilitated rapid synthesis of the daphnane/tigliane tricyclic core. Tetrahedron 73, 4172-4177. doi: $10.1016 /$ j.tet.2016.11.005 
Li, Z., Song, L., Meervelt, L. V., Tian, G., and Van der Eycken, E. V. (2018b). Cationic gold(I)-catalyzed cascade bicyclizations for divergent synthesis of (Spiro)polyheterocycles. ACS Catal. 8, 6388-6393. doi: $10.1021 /$ acscatal.8b01789

Liao, H., Leng, W. L., Le Mai Hoang, K., Yao, H., He, J., Voo, A. Y. H., et al. (2017). Asymmetric syntheses of 8-oxabicyclo[3,2,1]octane and 11-oxatricyclo[5.3.1.0] undecane from glycals. Chem. Sci. 8, 6656-6661. doi: $10.1039 / \mathrm{c} 7 \mathrm{sc} 02625 \mathrm{k}$

Liu, R., Wang, Q., Wei, Y., and Shi, M. (2018). Synthesis of indolizine derivatives containing eight-membered rings: via a gold-catalyzed two-fold hydroarylation of diynes. Chem. Commun. 54, 1225-1228. doi: 10.1039/c7cc09250d

Lu, X.-L., Lyu, M.-Y., Peng, X.-S., and Wong, H. N. C. (2018). Gold(I)-catalyzed tandem cycloisomerization of 1,5-enyne ethers by hydride transfer. Angew. Chem. Int. Ed. 57, 11365-11368. doi: 10.1002/anie.201806842

Luo, K., Cao, T., Jiang, H., Chen, L., and Zhu, S. (2017). Gold-catalyzed ring expansion of enyne-lactone: generation and transformation of 2-oxoninonium. Org. Lett. 19, 5856-5859. doi: 10.1021/acs.orglett.7b02834

Luo, K., Zhang, L., Jiang, H., Chen, L., and Zhu, S. (2018). Selectivityswitchable construction of benzo-fused polycyclic compounds through a gold-catalyzed reaction of enyne-lactone. Chem. Commun. 54, 1893-1896. doi: $10.1039 / \mathrm{c} 7 \mathrm{cc} 09786 \mathrm{~g}$

Maes, B., Cossy, J., and Polanc, S. (2016). Au-Catalyzed Synthesis and Functionalization of Heterocycles, Vol. 46. Basel: Springer Nature.

Magné, V., Lorton, C., Marinetti, A., Guinchard, X., and Voituriez, A. (2017). Short enantioselective total synthesis of (-)-rhazinilam using a gold(I)-catalyzed cyclization. Org. Lett. 19, 4794-4797. doi: 10.1021/acs.orglett.7b02210

Mandal, N., and Datta, A. (2018). Gold(I)-catalyzed intramolecular diels-alder reaction: evolution of trappable intermediates via asynchronous transition states. J. Org. Chem. 83, 11167-11177. doi: 10.1021/acs.joc.8b01752

McCarter, A. W., Sommer, M., Percy, J. M., Jamieson, C., Kennedy, A. R., and Hirst, D. J. (2018). Atom efficient synthesis of selectively difluorinated carbocycles through a gold(I) catalyzed cyclization. J. Org. Chem. 83, 88888905. doi: 10.1021/acs.joc.8b01121

McGee, P., Brousseau, J., and Barriault, L. (2018). Development of new gold (I)catalyzed carbocyclizations and their applications in the synthesis of natural products. Isr. J. Chem. 58, 511-520. doi: 10.1002/ijch.201700054

Mizushima, E., Sato, K., Hayashi, T., and Tanaka, M. (2002). Highly efficient aui-catalyzed hydration of alkynes. Angew. Chem. Int. Ed. 41, 4563-4565. doi: 10.1002/1521-3773(20021202)41:23<4563::AID-ANIE4563>3.0.CO;2-U

Morita, T., Fukuhara, S., Fuse, S., and Nakamura, H. (2018). Gold(I)-catalyzed intramolecular SEAr reaction: efficient synthesis of isoxazole-containing fused heterocycles. Org. Lett. 20, 433-436. doi: 10.1021/acs.orglett.7b03760

Muratore, M. E., Konovalov, A. I., Armengol-Relats, H., and Echavarren, A. M. (2018). Diastereospecific gold(I)-catalyzed cyclization cascade for the controlled preparation of N- and N,O-heterocycles. Chem. Eur. J., 1561315621. doi: $10.1002 /$ chem. 201802770

Nahide, P. D., Jiménez-Halla, J. O. C., Wrobel, K., Solorio-Alvarado, C. R., Ortiz Alvarado, R., and Yahuaca-Juárez, B. (2018). Gold(I)-catalysed high-yielding synthesis of indenes by direct Csp3-H bond activation. Org. Biomol. Chem. 16, 7330-7335. doi: 10.1039/C8OB02056F

Naoe, S., Yoshida, Y., Oishi, S., Fujii, N., and Ohno, H. (2016). Total synthesis of $(+)$-conolidine by the gold(I)-catalyzed cascade cyclization of a conjugated enyne. J. Org. Chem. 81, 5690-5698. doi: 10.1021/acs.joc.6b00720

Nechaev, A. A., Van Hecke, K., Zaman, M., Kashtanov, S., Ungur, L., Pereshivko, O. P., et al. (2018). Gold-catalyzed post-ugi ipso-cyclization with switchable diastereoselectivity. J. Org. Chem. 83, 8170-8182. doi: 10.1021/acs.joc.8b00953

Obradors, C., and Echavarren, A. M. (2014). Gold-catalyzed rearrangements and beyond. Acc. Chem. Res. 47, 902-912. doi: 10.1021/ar400174p

Odabachian, Y., Le Goff, X. F., and Gagosz, F. (2009). An unusual access to medium sized cycloalkynes by a new gold(i)-catalysed cycloisomerisation of diynes. Chem. Eur. J. 15, 8966-8970. doi: 10.1002/chem. 200901312

Pan, F., Shu, C., and Ye, L. W. (2016). Recent progress towards gold-catalyzed synthesis of N-containing tricyclic compounds based on ynamides. Org. Biomol. Chem. 14, 9456-9465. doi: 10.1039/c6ob01774f

Patel, D. S., and Bharatam, P. V. (2011). To bend or not to bend! the dilemma of allenes. J. Org. Chem. 76, 2558-2567. doi: 10.1021/jo102432a

Peng, X., Zhu, L., Hou, Y., Pang, Y., Li, Y., Fu, J., et al. (2017). Access to Benzo[a]carbazoles and Indeno[1,2-c]quinolines by a Gold(I)-Catalyzed
Tunable Domino Cyclization of Difunctional 1,2-Diphenylethynes. Org. Lett. 19, 3402-3405. doi: 10.1021/acs.orglett.7b01358

Pérez-Galán, P., Waldmann, H., and Kumar, K. (2016). Building polycyclic indole scaffolds via gold(I)-catalyzed intra- and inter-molecular cyclization reactions of 1,6-enynes. Tetrahedron 72, 3647-3652. doi: 10.1016/j.tet.2016. 03.020

Quintavalla, A., and Bandini, M. (2016). Gold-catalyzed allylation reactions. ChemCatChem 8, 1437-1453. doi: 10.1002/cctc.201600071

Ranieri, B., Escofet, I., and Echavarren, A. M. (2015). Anatomy of gold catalysts: facts and myths. Org. Biomol. Chem. 13, 7103-7118. doi: 10.1039/c5ob00736d

Rao, W., Boyle, J. W., and Chan, P. W. H. (2016). Gold-catalyzed sequential cyclization of 1-En-3,9-diyne esters to partially hydrogenated 3H-Dicyclopenta[a,b]naphthalenes. Chem. Eur. J. 22, 6532-6536. doi: 10.1002/chem.201600915

Reeves, R. D., Phelps, A. M., Raimbach, W. A., and Schomaker, J. M. (2017). Diastereoselective Au-catalyzed allene cycloisomerizations to highly substituted cyclopentenes. Org. Lett. 19, 3394-3397. doi: 10.1021/acs.orglett.7b01350

Reiersølmoen, A. C., Østrem, E., and Fiksdahl, A. (2018). Gold(III)-catalysed cis -to- trans cyclopropyl isomerization. Eur. J. Org. Chem. 2018, 3317-3325. doi: 10.1002/ejoc.201800419

Riedel, S., Maichle-Mössmer, C., and Maier, M. E. (2017). Intramolecular diels-alder reactions of tethered enoate substituted furans induced by dialkylaluminum chloride. J. Org. Chem. 82, 12798-12805. doi: 10.1021 /acs.joc.7b02117

Rinaldi, A., Petrović, M., Magnolfi, S., Scarpi, D., and Occhiato, E. G. (2018). Pentannulation reaction by tandem Gold(I)-catalyzed propargyl claisen rearrangement/nazarov cyclization of enynyl vinyl ethers. Org. Lett. 20, 47134717. doi: 10.1021/acs.orglett.8b02141

Rocchigiani, L., Jia, M., Bandini, M., and Macchioni, A. (2015). Assessing the role of counterion in gold-catalyzed dearomatization of indoles with allenamides by nmr studies. ACS Catalysis 5, 3911-3915. doi: 10.1021/acscatal.5b00502

Sahoo, A. K., Prabagar, B., Mallick, R. K., Prasad, R., and Gandon, V. (2018). Umpolung reactivity of ynamides: an unconventional [1,3]-sulfonyl and [1,5]sulfinyl migration cascade. Angew. Chem. Int. Ed. doi: 10.1002/anie.201813143

Sanjuán, A. M., Rashid, M. A., García-García, P., Martínez-Cuezva, A., Fernández-Rodríguez, M. A., Rodríguez, F., et al. (2015). Gold(I)-catalyzed cycloisomerizations and alkoxycyclizations of ortho-(alkynyl)styrenes. Chem. Eur. J. 21, 3042-3052. doi: 10.1002/chem.201405789

Sanjuán, A. M., Virumbrales, C., García-García, P., Fernández-Rodríguez, M. A., and Sanz, R. (2016). Formal $[4+1]$ cycloadditions of $\beta, \beta$-diaryl-substituted ortho-(Alkynyl)styrenes through Gold(I)-catalyzed cycloisomerization reactions. Org. Lett. 18, 1072-1075. doi: 10.1021/acs.orglett.6b00191

Schießl, J., Schulmeister, J., Doppiu, A., Wörner, E., Rudolph, M., Karch, R., et al. (2018a). An industrial perspective on counter anions in gold catalysis: on alternative counter anions. Adv. Synth. Catal. 360, 3949-3959. doi: $10.1002 /$ adsc. 201800629

Schießl, J., Schulmeister, J., Doppiu, A., Wörner, E., Rudolph, M., Karch, R., et al. (2018b). An industrial perspective on counter anions in gold catalysis: underestimated with respect to "Ligand Effects". Adv. Synth. Catal. 360, 24932502. doi: 10.1002/adsc.201800233

Sekine, K., Stuck, F., Schulmeister, J., Wurm, T., Zetschok, D., Rominger, F., et al. (2018). N-heterocycle-fused pentalenes by a gold-catalyzed annulation of diethynyl-quinoxalines and -phenazines. Chem. Eur. J. 24, 12515-12518. doi: 10.1002/chem.201803096

Shen, W.-B., Zhou, B., Zhang, Z.-X., Yuan, H., Fang, W., and Ye, L.-W. (2018). Gold-catalyzed cascade cyclization of $\mathrm{N}$-propargyl ynamides: rapid access to functionalized indeno[1,2- c ]pyrroles. Org. Chem. Front. 5, 2468-2472. doi: $10.1039 / C 8 Q 000552 \mathrm{D}$

Siva Kumari, A. L., Siva Reddy, A., and Swamy, K. C. (2016). Exploring the gold mine: $[\mathrm{Au}]$-catalysed transformations of enynals, enynones and enynols. Org. Biomol. Chem. 14, 6651-6671. doi: 10.1039/c6ob00698a

Soriano, E., and Fernández, I. (2014). Allenes and computational chemistry: from bonding situations to reaction mechanisms. Chem. Soc. Rev. 43, 3041-3105. doi: $10.1039 / \mathrm{c} 3 \operatorname{cs} 60457 \mathrm{~h}$

Stathakis, C. I., Gkizis, P. L., and Zografos, A. L. (2016). Metal-catalyzed cycloisomerization as a powerful tool in the synthesis of complex sesquiterpenoids. Nat. Prod. Rep. 33, 1093-1117. doi: 10.1039/c6np00026f 
Stephen, A., Hashmi, K., Braun, I., Rudolph, M., and Rominger, F. (2012). The role of gold acetylides as a selectivity trigger and the importance of gem-diaurated species in the gold-catalyzed hydroarylating-aromatization of arene-diynes. Organometallics 31, 644-661. doi: 10.1021/om200946m

Stephen, A., Hashmi, K., Schwarz, L., Choi, J. H., and Frost, T. M. (2000). A new gold-catalyzed C-C bond formation. Angew. Chem. - Int. Ed. 39, 2285-2288. doi: 10.1002/1521-3773(20000703)39

Suárez, A., Suárez-Pantiga, S., Nieto-Faza, O., and Sanz, R. (2017). Gold-catalyzed synthesis of 1-(indol-3-yl)carbazoles: selective 12 -alkyl vs 12 -vinyl migration. Org. Lett. 19, 5074-5077. doi: 10.1021/acs.orglett.7b02303

Sun, H., Xu, S., Xing, Z., Liu, L., Feng, S., Fang, B., et al. (2017). Rapid construction of complex tetracyclic frameworks via a gold(i)-catalyzed tandem 1,2-acyloxy migration/[3 +2$]$ cycloaddition/Friedel-Crafts type cyclization reaction of linear enynyl esters. Org. Chem. Front. 4, 2109-2113. doi: 10.1039/c7qo00511c

Sun, N., Xie, X., Chen, H., and Liu, Y. (2016). Gold-catalyzed cyclization of furan-ynes bearing a propargyl carbonate group: intramolecular diels-alder reaction with in situ generated allenes. Chem. Eur. J. 22, 14175-14180. doi: 10.1002/chem.201603055

Swift, C. A., and Gronert, S. (2016). Gold(I)-induced rearrangements of propargyl derivatives: a gas-phase study. Organometallics 35, 3844-3851. doi: 10.1021/acs.organomet.6b00719

Teles, J. H., Brode, S., and Chabanas, M. (1998). Cationic gold(i) complexes: highly efficient catalysts for the addition of alcohols to alkynes. Angew. Chem. Int. Ed. $37,1415-1418$

Thummanapelli, S. K., Hosseyni, S., Su, Y., Akhmedov, N. G., and Shi, X. (2016). Ligand-controlled gold-catalyzed cycloisomerization of $1, n$-enyne esters toward synthesis of dihydronaphthalene. Chem. Commun. 52, 76877690. doi: 10.1039/c6cc03032g

Timmerman, J. C., Laulhé, S., and Widenhoefer, R. A. (2017). Gold(I)-catalyzed intramolecular hydroamination of unactivated terminal and internal alkenes with 2-pyridones. Org. Lett. 19, 1466-1469. doi: 10.1021/acs.orglett.7b00450

Toullec, P. Y., and Michelet, V. (2018). Gold-catalyzed polycyclization toward natural products synthesis. Isr. J. Chem. 58, 578-585. doi: 10.1002/ijch.201800002

Trommenschlager, A., Chotard, F., Bertrand, B., Amor, S., Dondaine, L., Picquet, M., et al. (2017). Gold(i)-BODIPY-imidazole bimetallic complexes as new potential anti-inflammatory and anticancer trackable agents. Dalt. Trans. 46, 8051-8056. doi: $10.1039 / \mathrm{c} 7 \mathrm{dt} 01377 \mathrm{a}$

Tšupova, S., Hansmann, M. M., Rudolph, M., Rominger, F., and Hashmi, A. S. K. (2017). Gold-catalyzed formal cyclisation/dimerization of thiophene-tethered diynes. Chem. Eur. J. 23, 5716-5721. doi: 10.1002/chem.201700061

Wang, W., Hammond, G. B., and Xu, B. (2012). Ligand effects and ligand design in homogeneous gold(I) catalysis. J. Am. Chem. Soc. 134, 5697-5705. doi: $10.1021 / \mathrm{ja} 3011397$

Wang, Y.-M., Lackner, A. D., and Toste, F. D. (2014). Development of catalysts and ligands for enantioselective gold catalysis. Acc. Chem. Res. 47, 889-901. doi: $10.1021 / \mathrm{ar} 400188 \mathrm{~g}$

Wang, Z., Nicolini, C., Hervieu, C., Wong, Y. F., Zanoni, G., and Zhang, L. (2017a). Remote cooperative group strategy enables ligands for accelerative asymmetric gold catalysis. J. Am. Chem. Soc. 139, 16064-16067. doi: 10.1021/jacs.7b09136

Wang, Z., Ying, A., Fan, Z., Hervieu, C., and Zhang, L. (2017b). Tertiary amino group in cationic gold catalyst: tethered frustrated lewis pairs that enable ligand-controlled regiodivergent and stereoselective isomerizations of propargylic esters. ACS Catal. 7, 3676-3680. doi: 10.1021/acscatal.7b00626

Wei, L. S., He, G. X., Kong, X. F., Pan, C. X., Mo, D. L., and Su, G. F. (2018). Gold(III)-catalyzed selective cyclization of alkynyl quinazolinonetethered pyrroles: synthesis of fused quinazolinone scaffolds. J. Org. Chem. 83, 6719-6727. doi: 10.1021/acs.joc.8b00168

Wei, Y., and Shi, M. (2016). Divergent synthesis of carbo- and heterocycles via gold-catalyzed reactions. ACS Catal. 6, 2515-2524. doi: 10.1021/acscatal.6b00048

Wildermuth, R., Speck, K., and Magauer, T. (2016). Gold(i)-catalyzed enyne cyclizations: studies toward the total synthesis of $(+)$-aureol. Synthesis 48, 1814-1824. doi: 10.1055/s-0035-1561589

Wu, Z., Lebœuf, D., Retailleau, P., Gandon, V., Marinetti, A., and Voituriez, A. (2017). Enantioselective gold(i)-catalyzed rearrangement of cyclopropylsubstituted 1,6-enynes into 2-oxocyclobutyl-cyclopentanes. Chem. Commun. 53, 7026-7029. doi: 10.1039/c7cc03234j
Wurm, T., Bucher, J., Rudolph, M., Rominger, F., and Hashmi, A. S. K. (2017). On the gold-catalyzed generation of phenyl cations from 1,5-diynes. Adv. Synth. Catal. 359, 1637-1642. doi: 10.1002/adsc.201700231

Wurm, T., Rüdiger, E. C., Schulmeister, J., Koser, S., Rudolph, M., Rominger, F., et al. (2018). A golden access to acenopentalenes. Chem. Eur. J. 24, 2735-2740. doi: 10.1002/chem.201705456

Xie, J., Pan, C., Abdukader, A., and Zhu, C. (2014). Gold-catalyzed C(sp3)-H bond functionalization. Chem. Soc. Rev. 43, 5245-5256. doi: 10.1039/c4cs00004h

Xiong, Z., Zhang, X., Li, Y., Peng, X., Fu, J., Guo, J., et al. (2018). Syntheses of $12 \mathrm{H}$ -benzo[ a ]xanthen-12-ones and benzo[ a ]acridin-12(7 H )-ones through $\mathrm{Au}($ i )-catalyzed Michael addition/6- endo -trig cyclization/aromatization cascade annulation. Org. Biomol. Chem. 16, 7361-7374. doi: 10.1039/C8OB01684D

Xu, W., Wang, G., Xie, X., and Liu, Y. (2018). Gold(I)-catalyzed formal intramolecular dehydro-diels-alder reaction of ynamide-ynes: synthesis of functionalized benzo[ b]carbazoles. Org. Lett. 20, 3273-3277. doi: 10.1021/acs.orglett.8b01145

Yamamoto, Y. (2012). Transition-metal-catalyzed cycloisomerizations of $\alpha, \omega-$ dienes. Chem. Rev. 112, 4736-4769. doi: 10.1021/cr300050n

Yang, W., and Hashmi, A. S. K. (2014). Mechanistic insights into the gold chemistry of allenes. Chem. Soc. Rev. 43, 2941-2955. doi: 10.1039/c3cs60441a

Ye, L., Wang, Y., Aue, D. H., and Zhang, L. (2012). Experimental and computational evidence for gold vinylidenes: generation from terminal alkynes via a bifurcation pathway and facile C-H insertions. J. Am. Chem. Soc. 134, 31-34. doi: 10.1021/ja2091992

Yuan, B., He, R., Guo, X., Shen, W., Zhang, F., Xu, Y., et al. (2018). DFT study on the $\mathrm{Au}(\mathrm{i})$-catalyzed cyclization of indole-allenoate: counterion and solvent effects. New J. Chem. 42, 15618-15628. doi: 10.1039/C8NJ02375A

Zamani, F., Babaahmadi, R., Yates, B., Gardiner, M. G., Ariafard, A., Pyne, S. G., et al. (2019). Dual gold-catalyzed cycloaromatization of unconjugated (E)-enediynes. Angew. Chem. Int. Ed. 58, 2114-2119. doi: 10.1002/anie.2018 10794

Zhang, D. H., Zhang, Z., and Shi, M. (2012). Transition metal-catalyzed carbocyclization of nitrogen and oxygen-tethered 1,n-enynes and diynes: synthesis of five or six-membered heterocyclic compounds. Chem. Commun. 48, 10271-10279. doi: 10.1039/c2cc34739c

Zhang, J., Liao, Z., Chen, L., Jiang, H., and Zhu, S. (2018a). Catalytic [1,3] O-toC rearrangement: rapid access to bridged bicyclic systems. Chem. Eur. J. 24, 6927-6931. doi: 10.1002/chem.201801062

Zhang, J.-h., Wei, Y., and Shi, M. (2018b). Gold-catalyzed ring enlargement and cycloisomerization of alkynylamide tethered alkylidenecyclopropanes. Org. Chem. Front. 5, 2980-2985. doi: 10.1039/C8QO00907D

Zheng, Y., Guo, L., and Zi, W. (2018). Enantioselective and regioselective hydroetherification of alkynes by gold-catalyzed desymmetrization of prochiral phenols with P-stereogenic centers. Org. Lett. 20, 7039-7043. doi: 10.1021/acs.orglett.8b02982

Zhong, C. Z., Tung, P. T., Chao, T. H., and Yeh, M. C. P. (2017). Goldcatalyzed stereoselective synthesis of bicyclic lactams and ketones from N-tosylynamidomethyl-tethered cyclohexenes. J. Org. Chem. 82, 481-501. doi: 10.1021/acs.joc.6b02479

Zhou, J., Fu, C., and Ma, S. (2018a). Gold-catalyzed stereoselective cycloisomerization of allenoic acids for two types of common natural $\gamma$-butyrolactones. Nat. Commun. 9, 1-10. doi: 10.1038/s41467-018-03894-6

Zhou, L., Zhang, Y., Fang, R., and Yang, L. (2018b). Computational exploration of counterion effects in gold(I)-catalyzed cycloisomerization of ortho (Alkynyl)styrenes. ACS Omega 3, 9339-9347. doi: 10.1021/acsomega.8b01131

Conflict of Interest Statement: The authors declare that the research was conducted in the absence of any commercial or financial relationships that could be construed as a potential conflict of interest.

Copyright () 2019 Marin-Luna, Nieto Faza and Silva López. This is an open-access article distributed under the terms of the Creative Commons Attribution License (CC $B Y)$. The use, distribution or reproduction in other forums is permitted, provided the original author(s) and the copyright owner(s) are credited and that the original publication in this journal is cited, in accordance with accepted academic practice. No use, distribution or reproduction is permitted which does not comply with these terms. 